\title{
Effectiveness of Different Urban Heat Island Mitigation Methods and Their Regional Impacts
}

\author{
NING ZHANG \\ CMA-NJU Joint Laboratory for Climate Prediction Studies, Institute for Climate \\ and Global Change Research, School of Atmospheric Sciences, Nanjing University, \\ and Jiangsu Collaborative Innovation Center for Climate Change, Nanjing, China \\ YAN CHEN \\ Jiangsu Climate Center, Nanjing, China \\ LING LUO \\ Zhejiang Province Meteorological Observatory, Hangzhou, China \\ YONGWEI WANG \\ School of Atmospheric Physics, Nanjing University of Information Science and Technology, Nanjing, China
}

(Manuscript received 1 April 2017, in final form 10 September 2017)

\begin{abstract}
Cool roofs and green roofs are two popular methods to mitigate the urban heat island and improve urban climates. The effectiveness of different urban heat island mitigation strategies in the summer of 2013 in the Yangtze River delta, China, is investigated using the Weather Research and Forecasting (WRF) Model coupled with a physically based single-layer urban canopy model. The modifications to the roof surface changed the urban surface radiation balance and then modified the local surface energy budget. Both cool roofs and green roofs led to a lower surface skin temperature and near-surface air temperature. Increasing the roof albedo to 0.5 caused a similar effectiveness as covering $25 \%$ of urban roofs with vegetation; increasing the roof albedo to 0.7 caused a similar near-surface air temperature decrease as $50 \%$ green roof coverage. The near-surface relative humidity increased in both cool roof and green roof experiments because of the combination of the impacts of increases in specific humidity and decreases in air temperature. The regional impacts of cool roofs and green roofs were evaluated using a regional effect index. A regional impact was found for near-surface air temperature and specific/relative humidity when the percentage of roofs covered with high-albedo materials or green roofs reached a higher fraction (greater than $50 \%$ ). The changes in the vertical profiles of temperature cause a more stable atmospheric boundary layer over the urban area; at the same time, the crossover phenomena occurred above the boundary layer due to the decrease in vertical wind speed.
\end{abstract}

\section{Introduction}

A heat wave is a long period of excessively hot weather, which can impact human health (Guirguis et al. 2014) and is one of the weather-related causes of human death (Harlan et al. 2006; Gosling et al. 2007; Kovats and Hajat 2008; Gosling et al. 2009; Wu et al. 2014; Roldan et al. 2016). Both observations and numerical simulations have shown that heat waves have become more frequent and longer over the past few decades (Hansen

Corresponding author: Ning Zhang, ningzhang@nju.edu.cn et al. 2010; Coumou and Rahmstorf 2012; Tanarhte et al. 2015; Lelieveld et al. 2016), and this trend will continue in the future due to global climate change (Gershunov et al. 2009; Perkins et al. 2012; Smith et al. 2013).

Heat waves typically result from synoptic-scale temperature anomalies (Loikith and Broccoli 2012; Meehl and Tebaldi 2004), but in cities, urbanization also plays an important role in heat waves. Urbanization modifies the physical properties of the land surface and changes the energy and moisture exchange between the ground surface and the atmosphere compared to natural landscapes. The changes 
(a)

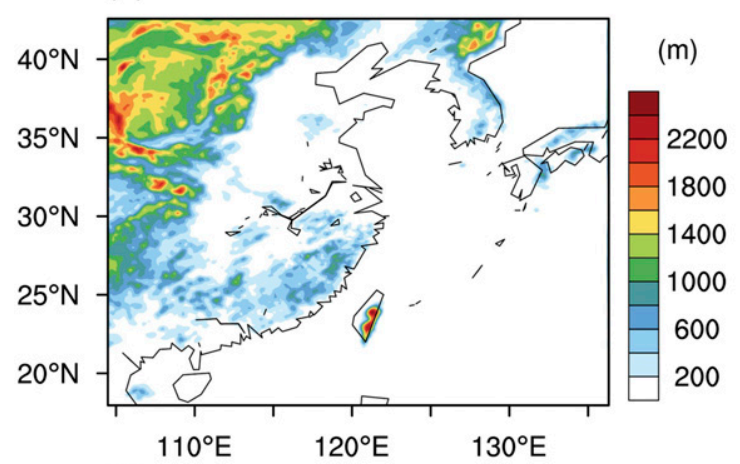

(b)

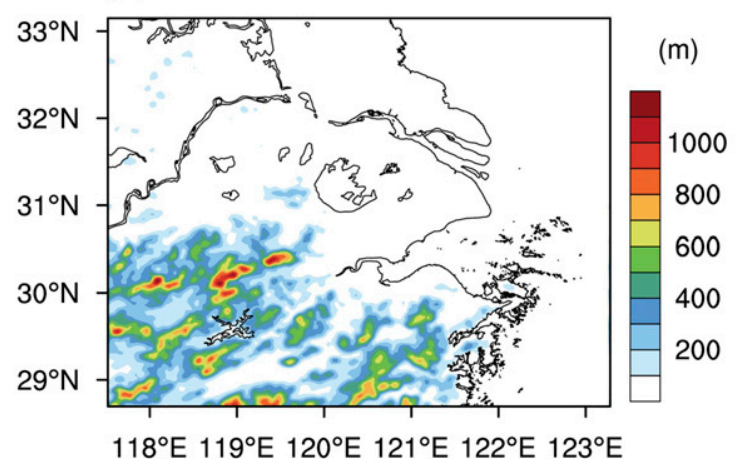

(c)

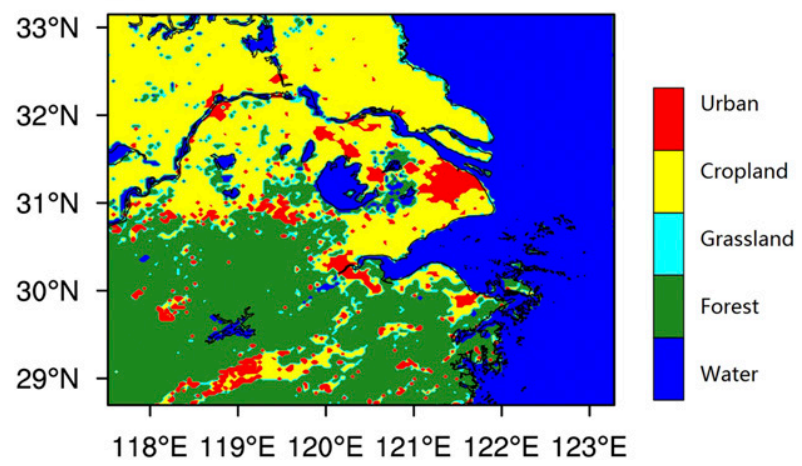

FIG. 1. The simulated domains: (a) the topography of domain 1 and the (b) topography and (c) land use types of domain 2.

in land surface energy budgets cause warm surface layers over cities and form the urban heat island (UHI) phenomenon. The UHI may exacerbate heat waves over urban areas due to the low vegetation cover and less evapotranspiration in cities; these impacts have been proven by both observations and numerical simulations (Grimmond 2007; Sugawara et al. 2008; Basara et al. 2010; Zhou and Shepherd 2010; Zhang et al. 2011; Li and Bou-Zeid 2013; Perkins and Alexander 2013; Huang and Lu 2015; Y. Sun et al. 2016; J. Wang et al. 2016).

Although urban areas cover less than $0.5 \%$ of Earth's land surface (Schneider et al. 2009), more than 50\%
TABLE 1. Parameters for the SLUCM. Three different values of ZR, ROAD_WIDTH, ROOF_WIDTH, and SDZR are used for the low intensity, medium intensity, and commercial urban land cover types.

\begin{tabular}{|c|c|c|}
\hline Parameters & Default & Description \\
\hline ALBR & 0.2 & Roof albedo \\
\hline ALBB & 0.2 & Wall albedo \\
\hline ALBG & 0.2 & Road albedo \\
\hline EPSR & 0.9 & Roof emissivity \\
\hline EPSB & 0.9 & Wall emissivity \\
\hline EPSG & 0.95 & Road emissivity \\
\hline AKSR & 0.67 & $\begin{array}{l}\text { Conductivity of roof } \\
\text { materials }\left(\mathrm{W} \mathrm{m}^{-1} \mathrm{~K}^{-1}\right)\end{array}$ \\
\hline AKSB & 0.67 & $\begin{array}{l}\text { Conductivity of wall } \\
\text { materials }\left(\mathrm{W} \mathrm{m}^{-1} \mathrm{~K}^{-1}\right)\end{array}$ \\
\hline AKSG & 0.40 & $\begin{array}{l}\text { Conductivity of road } \\
\text { materials }\left(\mathrm{W} \mathrm{m}^{-1} \mathrm{~K}^{-1}\right)\end{array}$ \\
\hline CAPR & 1.0 & $\begin{array}{l}\text { Heat capacity of roof } \\
\text { materials }\left(\mathrm{MJ} \mathrm{m}^{-3} \mathrm{~K}^{-1}\right)\end{array}$ \\
\hline CAPB & 1.0 & $\begin{array}{l}\text { Heat capacity of wall } \\
\text { materials }\left(\mathrm{MJ} \mathrm{m}^{-3} \mathrm{~K}^{-1}\right)\end{array}$ \\
\hline CAPG & 1.4 & $\begin{array}{l}\text { Heat capacity of road } \\
\text { materials }\left(\mathrm{MJ} \mathrm{m}^{-3} \mathrm{~K}^{-1}\right)\end{array}$ \\
\hline ZR & $5.0,7.5,10.0$ & Roof height (m) \\
\hline ROOF_WIDTH & $8.3,9.4,10.0$ & Roof width (m) \\
\hline ROAD_WIDTH & $8.3,9.4,10.0$ & Road width (m) \\
\hline SDZR & $1.0,3.0,4.0$ & $\begin{array}{l}\text { Standard deviation of } \\
\text { roof height }(\mathrm{m})\end{array}$ \\
\hline
\end{tabular}

of the global population lives in cities (UN World Population Prospects 2014, https://esa.un.org/unpd/ wup/). In China, cities tripled in size and doubled in population over the past three decades (Schneider and Mertes 2014), and UHI-enhanced heat waves were reported in many cites (Tan et al. 2010; Wang and Gong 2010; Zhang et al. 2011). Mitigation of the urban heat island is an efficient method to reduce the health and environment risks of heat waves (Aflaki et al. 2016).

The typical ways to mitigate the urban heat island are the use of cool (high albedo) building materials or urban greenery. The first method reduces the solar radiation absorbed by urban facets, and the latter changes the surface energy flux partition (surface Bowen ratio). Given the limits of urban space and human vision comfort, cool roofs and green roofs are among the most popular methods in urban heat island mitigation (Rosenfeld et al. 1995; Silva et al. 2010; Li and Bou-Zeid 2013; Li et al. 2014; Li and Bou-Zeid 2014; Y. Wang et al. 2016).

Numerical models are useful and effective tools for evaluating the effectiveness of different urban heat island mitigation methods. Previous studies mostly focus on the building scale or neighborhood scale (Susca et al. 2011; T. Sun et al. 2013, 2014; Kong et al. 2016). 
TABLE 2. Building facet albedo values used in different numerical experiments.

\begin{tabular}{|c|c|c|c|c|c|c|c|}
\hline & CTL & CR050 & CR070 & GR025 & GR050 & GR070 & GR100 \\
\hline Roof albedo & 0.2 & 0.5 & 0.7 & 0.2 & 0.2 & 0.2 & 0.2 \\
\hline Wall albedo & 0.2 & 0.2 & 0.2 & 0.2 & 0.2 & 0.2 & 0.2 \\
\hline Road albedo & 0.2 & 0.2 & 0.2 & 0.2 & 0.2 & 0.2 & 0.2 \\
\hline Green roof fraction $(\%)$ & 0 & 0 & 0 & 25 & 50 & 70 & 100 \\
\hline
\end{tabular}

With the development of parameterization schemes of urban surface processes, some sophisticated urban canopy models have been implemented in regional climate models, and it is now possible to evaluate more than one mitigation strategy using the same model (Kusaka et al. 2001; Chen et al. 2011b; Wang et al. 2013; $\mathrm{Li}$ et al. 2014). The upscaling impacts of green and cool roofs on the scale of a single city have been investigated in different cities (Silva et al. 2010; Sharma et al. 2016; Y. Wang et al. 2016), while little attention has been paid to their regional impacts, especially in large urban agglomerations.

This paper focuses on the 2013 summer in eastern China, when a record-breaking heat wave occurred and lasted for the entire month of July and the first half of August, especially over the Yangtze River delta (YRD) area, the most urbanized area in China. The near-surface air temperature observations broke local historical records at many stations. At least 40 people died during the heat wave, according to the Xinhua news service (http://news.xinhuanet.com/ english/indepth/2013-08/13/c_132627590.htm). During the strong El Niño-Southern Oscillation (ENSO) episode in 2013, the July sea surface temperature (SST) over the middle North Atlantic was the warmest in the past 160 years, and the strong SST anomaly impacted the East Asian upper-level westerly jet and western Pacific subtropical high, then caused the surface air temperature variability over the Jianghuai-Jiangnan region (Wang et al. 2014; Y. Sun et al. 2014). Even though this heat wave was caused by anomalies in the large-scale atmospheric circulation, a positive feedback between urban warming and heat wave intensity during this long heat wave episode was also found (J. Wang et al. 2016; Y. Wang et al. 2016). A previous study showed that the urbanization in this area has been proven to have a regional climate impact (Zhang et al. 2010) by changing the surface energy balance and causing the urban heat island phenomenon. It is important to investigate the effectiveness of different urban heat island mitigation methods for better urban design and substantial development in this area. In this paper, the effectiveness of cool and green roofs and their regional climate impact will be investigated using a regional climate model, the Weather Research and Forecasting (WRF) Model, coupled with a singlelayer urban canopy model.

\section{Model description and numerical experiment design}

\section{a. WRF Model and the urban canopy parameterization schemes}

The WRF Model (version 3.8.0) is used as the numerical tool in this paper. It is a state-of-the-art atmospheric modeling system based on a fully compressible and nonhydrostatic dynamic core (https://www.mmm. ucar.edu/weather-research-and-forecasting-model). WRF is designed for both meteorological research and numerical weather prediction and excels in a broad range of applications across scales ranging from large-eddy

TABLE 3. Comparisons of simulated and observed near-surface meteorological parameters.

\begin{tabular}{|c|c|c|c|c|c|c|}
\hline & Meteorological parameters & MEAN $_{\mathrm{obs}}$ & $\mathrm{MEAN}_{\mathrm{sim}}$ & MB & $R$ & RMSE \\
\hline \multirow[t]{3}{*}{ All sites } & $T_{2 \mathrm{~m}}\left({ }^{\circ} \mathrm{C}\right)$ & 30.3 & 30.2 & 0.1 & 0.95 & 2.0 \\
\hline & $\mathrm{rh}_{2 \mathrm{~m}}(\%)$ & 68.2 & 61.4 & -6.8 & 0.80 & 6.8 \\
\hline & $U_{10 \mathrm{~m}}\left(\mathrm{~m} \mathrm{~s}^{-1}\right)$ & 2.4 & 1.8 & -0.6 & 0.72 & 0.89 \\
\hline \multirow[t]{3}{*}{ Urban stations } & $T_{2 \mathrm{~m}}\left({ }^{\circ} \mathrm{C}\right)$ & 30.8 & 31.0 & 0.2 & 0.95 & 1.9 \\
\hline & $\mathrm{rh}_{2 \mathrm{~m}}(\%)$ & 65.3 & 55.0 & -9.7 & 0.79 & 7.8 \\
\hline & $U_{10 \mathrm{~m}}\left(\mathrm{~m} \mathrm{~s}^{-1}\right)$ & 2.5 & 2.4 & -0.1 & 0.75 & 0.71 \\
\hline \multirow[t]{3}{*}{ Rural stations } & $T_{2 \mathrm{~m}}\left({ }^{\circ} \mathrm{C}\right)$ & 30.0 & 30.3 & 0.3 & 0.96 & 2.0 \\
\hline & $\mathrm{rh}_{2 \mathrm{~m}}(\%)$ & 69.8 & 64.8 & -5.0 & 0.81 & 5.5 \\
\hline & $U_{10 \mathrm{~m}}\left(\mathrm{~m} \mathrm{~s}^{-1}\right)$ & 2.6 & 1.9 & -0.7 & 0.69 & 1.0 \\
\hline
\end{tabular}



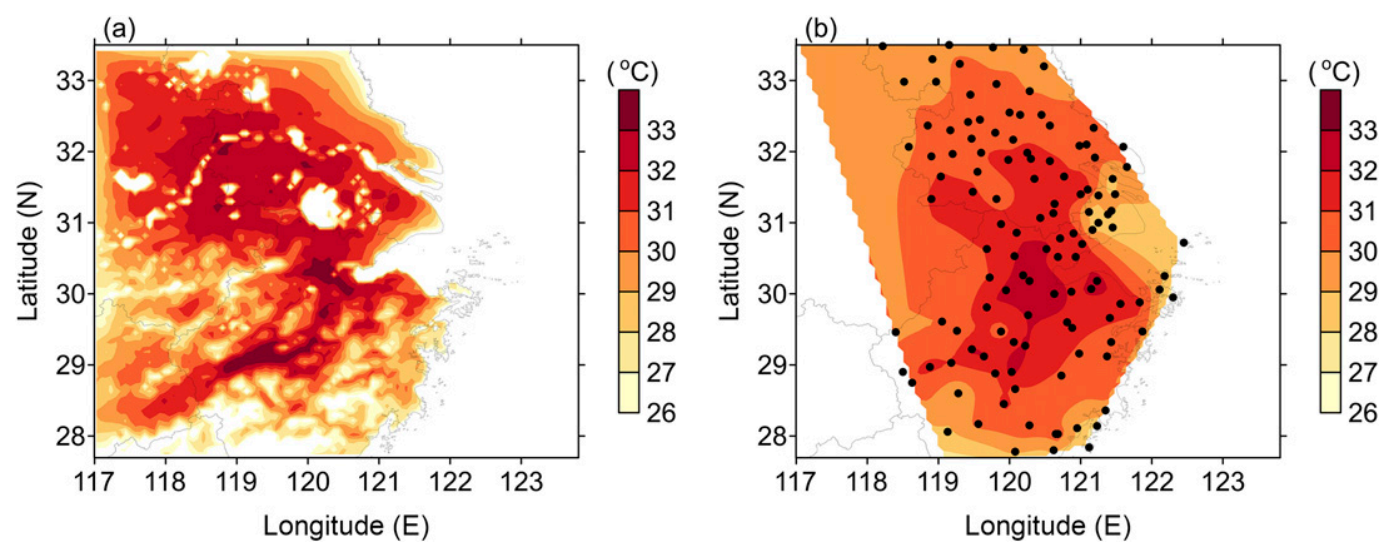

FIG. 2. The (a) simulated and (b) observed seasonal (JJA) mean near-surface temperature distributions; the black dots indicate the locations of meteorological stations.

simulations (tens of meters) to regional/global climate modeling (hundreds of kilometers). Currently, three urban canopy models have been implemented in the WRF Model: the single-layer urban canopy model (SLUCM; Kusaka et al. 2001; Kusaka and Kimura 2004), the multilayer Building Effect Parameterization
(BEP; Martilli et al. 2002), and a simple building energy model (BEM) coupled to BEP (Salamanca et al. 2010, 2011). All three urban canopy models are integrated in the Noah land surface model (Chen and Dudhia 2001; Ek et al. 2003) in WRF, and the SLUCM is widely used because of its reduced complexity (Miao
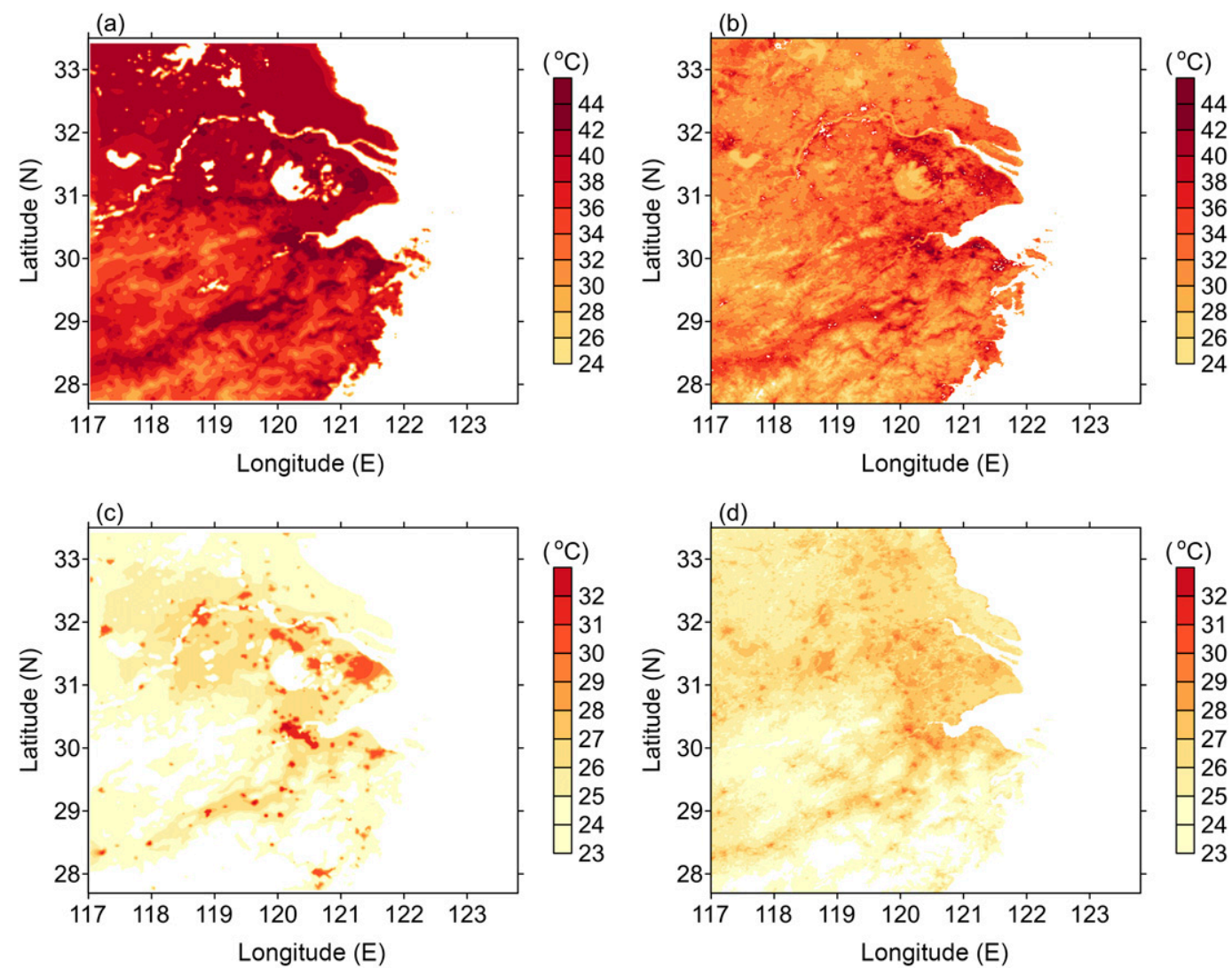

FIG. 3. The (a) simulated and (b) MODIS-observed daytime surface skin temperatures and the (c) simulated and (d) MODIS-observed nighttime surface skin temperatures. 

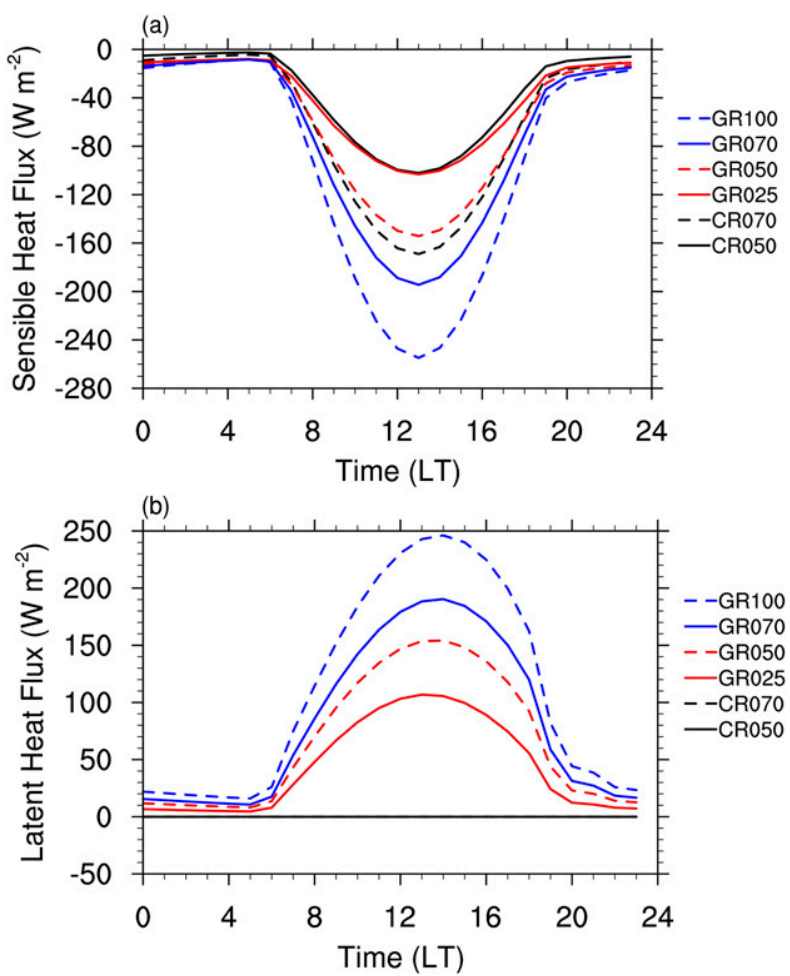

FIG. 4. The differences between sensitivity experiments and the CTL experiments in the diurnal variations of (a) sensible heat flux and (b) latent heat flux over urban areas.

and Chen 2008; Miao et al. 2009; Zhang et al. 2010; Chen et al. 2011a; Zhang et al. 2011; Kusaka et al. 2012a, 2012b; Grawe et al. 2013; Kang et al. 2014; Gutiérrez et al. 2015; Zhang et al. 2016). The SLUCM solves the radiative trapping within the urban canyon and an energy conservation equation for each urban surface (road, wall, and roof); each facet has its own thermal and radiation parameters (including albedo, emissivity, conductivity, and heat captivity; Kusaka et al. 2001). Recently, a multilayer green roof model has been integrated in the SLUCM and is available in the current release of WRF (Yang et al. 2015); these features make WRF-Noah-SLUCM a useful tool for evaluating the performances of cool and green roofs as UHI mitigation strategies.

\section{b. Numerical experiment design}

The model configuration consists of a parent domain and a nesting domain centered at $30.6^{\circ} \mathrm{N}, 120.4^{\circ} \mathrm{W}$, as shown in Fig. 1. The horizontal resolution of the outer domain is $15 \mathrm{~km}$, and that of the inner domain is $3 \mathrm{~km}$. The vertical grid system has 53 levels, and the model top is at $50 \mathrm{hPa}$; there are approximately 10 layers below $1000 \mathrm{~m}$. Initial and boundary conditions are provided by NCEP Final (FNL) data, with a horizontal resolution of $1^{\circ}$ and a temporal resolution of $6 \mathrm{~h}$. The model was constrained by boundary layer nudging, which means that the domain 1 simulation was driven by the FNL analysis data as the lateral boundary layer and the domain 2 simulations were driven by the domain 1 simulations. The default setting was used for the boundary nudging; five rows were used for the specified boundary value nudging with one row in the specific zone and four rows used as the relaxation zone. The model integrations are conducted from 0000 UTC 20 May (0800 LST 20 May) to 0000 UTC 1 September 2013, and the results of the summer season [June-August (JJA)] are analyzed in this paper. The physics packages used in the simulations include the Rapid Radiative Transfer Model for GCMs (RRTMG) for the longwave radiation and the Goddard scheme for the shortwave radiation processes, the BouLac scheme for the planetary boundary layer parameterization (Bougeault and Lacarrere 1989), as well as the Noah land surface model (LSM), which is coupled with the SLUCM (Chen et al. 2011b). The land use-land cover data of the 2013 MODIS data were used to represent the current urbanization conditions; the urban cover fraction of each grid was calculated with the 500-m-resolution MODIS land cover data of 2013 [Land Cover Type Yearly L3 Global 500m (MCD12Q1)], and the urban grid cells were classified into three types (commercial, urban cover fraction greater than $90 \%$; medium intensity, $50 \%-90 \%$; and low intensity, less than $50 \%$ ). The default physical parameters in the WRF release were used for the three urban types (Table 1), while the albedo or the vegetation cover fraction of the building roofs were modified in each sensitivity experiment, as shown in Table 2.

One control (CTL) and six additional numerical experiments were carried out to study the influence of different urban heat island mitigation scenarios, as shown in Table 1. Two cool roof and four green roof experiments were designed to study the effectiveness of the two different mitigation methods. The default urban parameters were used in the CTL experiments. In the cool roof experiments, the albedo of building roofs was modified to 0.50 and 0.70 , and the experiments were named CR050 and CR070, respectively. In the green roof experiments, the building roofs are hypothesized to be covered by vegetation in different fractions $(25 \%, 50 \%, 70 \%$, and $100 \%$, hereafter GR025, GR050, GR070, and GR100), and the vegetation cover is assumed to be homogeneous in a model grid. In the green roof experiments, an irrigation algorithm is used for the summer months of MaySeptember from 1800 to 2000 LST to enhance soil moisture (Yang et al. 2015). 

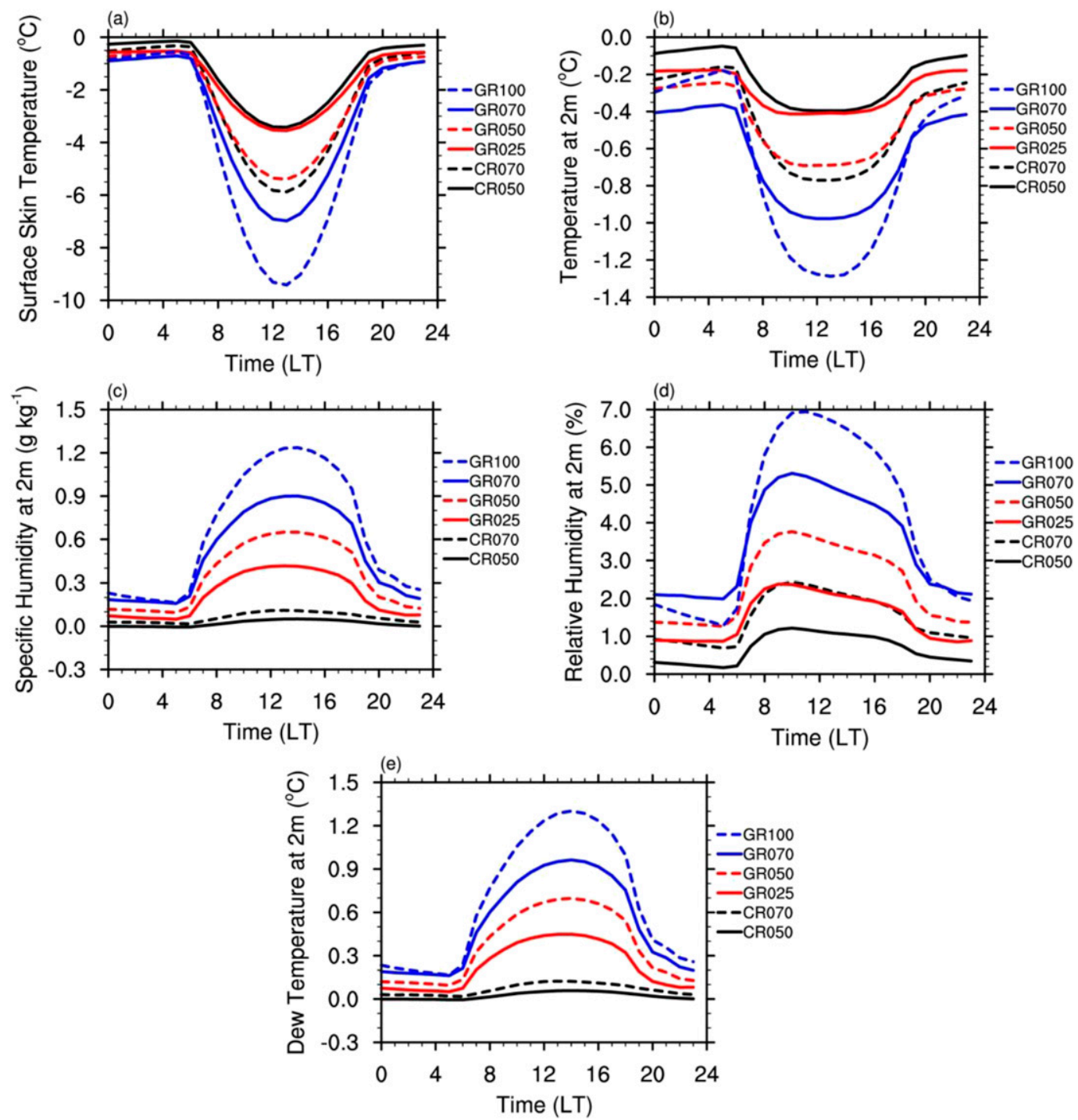

FIG. 5. The differences between sensitivity experiments and the CTL experiments in the diurnal variations of (a) surface skin temperature, (b) air temperature at $2 \mathrm{~m}$, (c) specific humidity at $2 \mathrm{~m}$, (d) relative humidity at $2 \mathrm{~m}$, and (e) dewpoint temperature at $2 \mathrm{~m}$.

Previous studies showed that urbanization not only changes local surface radiation, the energy budget, and local microclimate conditions, but may also cause regional impacts on surface meteorological fields and precipitation processes; the regional impact of urbanization was quantified using effect indexes (Trusilova et al. 2008;

TABLE 4. The regional EI of near-surface meteorological parameters under different urban heat island mitigation strategies.

\begin{tabular}{|c|c|c|c|c|c|c|}
\hline & CR050 & CR070 & GR025 & GR050 & GR070 & GR100 \\
\hline Air temperature at $2 \mathrm{~m}$ & 0.68 & 1.66 & 0.90 & 1.59 & 4.78 & 4.79 \\
\hline Maximum air temperature at $2 \mathrm{~m}$ & 0.92 & 2.46 & 1.04 & 2.56 & 5.32 & 5.42 \\
\hline Specific humidity at $2 \mathrm{~m}$ & 0.00 & 0.12 & 1.02 & 1.48 & 4.70 & 4.42 \\
\hline Dewpoint temperature at $2 \mathrm{~m}$ & 0.00 & 0.10 & 1.01 & 1.42 & 4.50 & 4.43 \\
\hline Relative humidity at $2 \mathrm{~m}$ & 0.18 & 1.05 & 0.98 & 1.34 & 4.53 & 4.53 \\
\hline PBLH & 1.49 & 3.00 & 1.66 & 2.40 & 5.20 & 5.10 \\
\hline
\end{tabular}


(a)

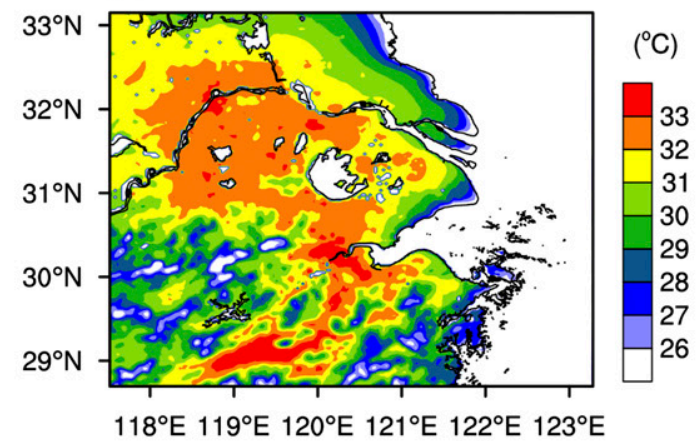

(b)

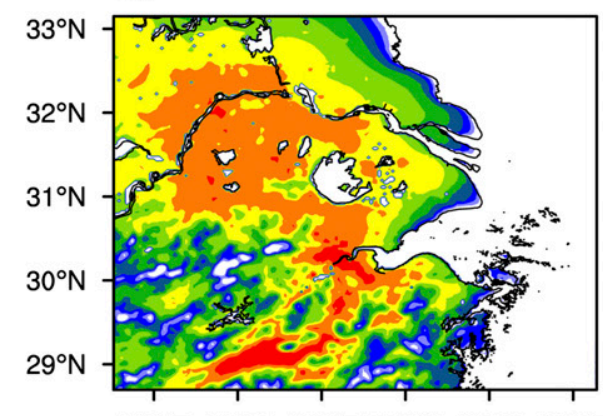

$118^{\circ} \mathrm{E} 119^{\circ} \mathrm{E} 120^{\circ} \mathrm{E} 121^{\circ} \mathrm{E} 122^{\circ} \mathrm{E} 123^{\circ} \mathrm{E}$ (d)

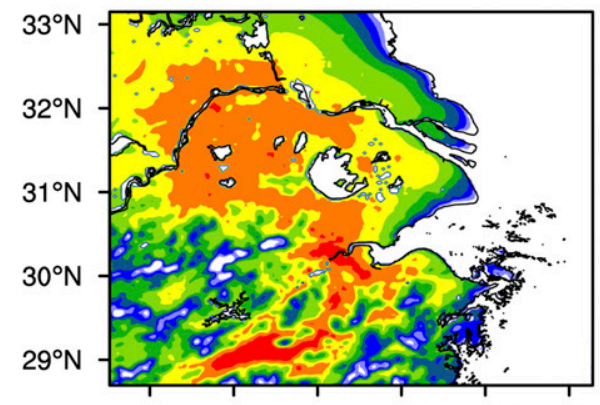

$118^{\circ} \mathrm{E} 119^{\circ} \mathrm{E} 120^{\circ} \mathrm{E} 121^{\circ} \mathrm{E} 122^{\circ} \mathrm{E} 123^{\circ} \mathrm{E}$

(f)

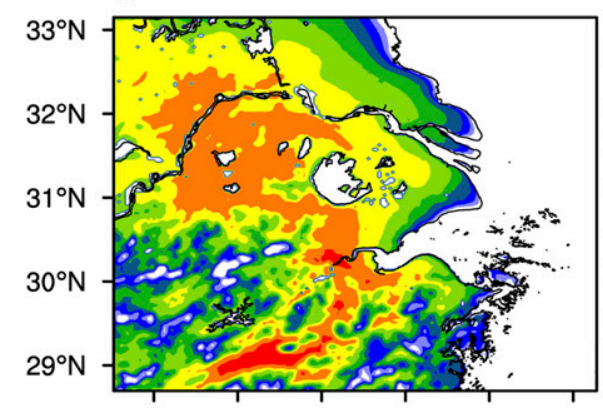

$118^{\circ} \mathrm{E} 119^{\circ} \mathrm{E} 120^{\circ} \mathrm{E} 121^{\circ} \mathrm{E} 122^{\circ} \mathrm{E} 123^{\circ} \mathrm{E}$ (c)

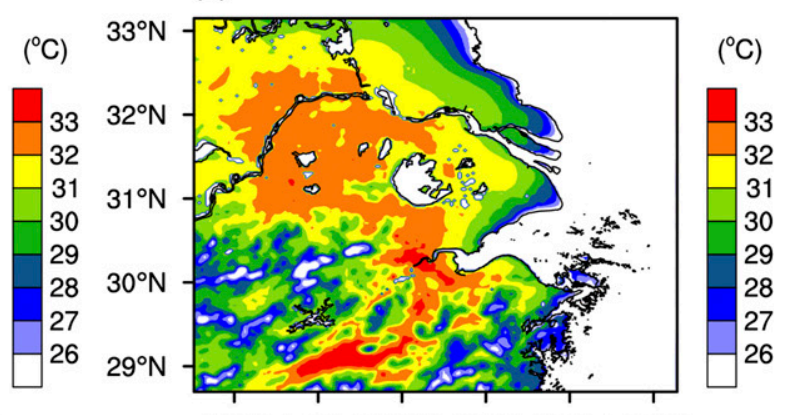

$118^{\circ} \mathrm{E} 119^{\circ} \mathrm{E} 120^{\circ} \mathrm{E} 121^{\circ} \mathrm{E} 122^{\circ} \mathrm{E} 123^{\circ} \mathrm{E}$ (e)

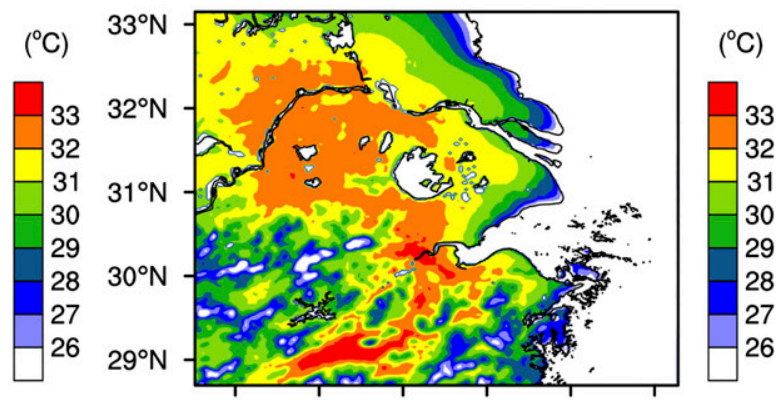

$118^{\circ} \mathrm{E} 119^{\circ} \mathrm{E} 120^{\circ} \mathrm{E} 121^{\circ} \mathrm{E} 122^{\circ} \mathrm{E} 123^{\circ} \mathrm{E}$ (g)

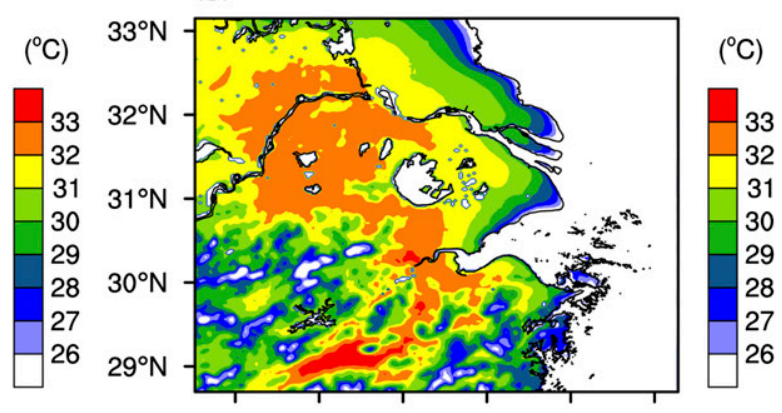

$118^{\circ} \mathrm{E} 119^{\circ} \mathrm{E} 120^{\circ} \mathrm{E} 121^{\circ} \mathrm{E} 122^{\circ} \mathrm{E} 123^{\circ} \mathrm{E}$

Fig. 6. Simulated averaged air temperature at $2 \mathrm{~m}$ in the (a) CTL, (b) CR050, (c) CR070, (d) GR025, (e) GR050, (f) GR070, and (g) GR100 experiments.

Zhang et al. 2010; Grawe et al. 2013). Following the method of Zhang et al. (2010), the differences between sensitivity experiments and the CTL experiments were used to observe the effectiveness and influence of the two mitigation methods, and we defined the effect index (EI) of urban heat island mitigations as follows: 
(a)

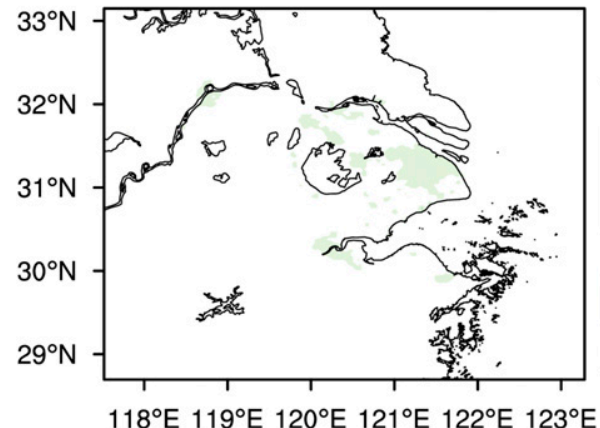

(c)

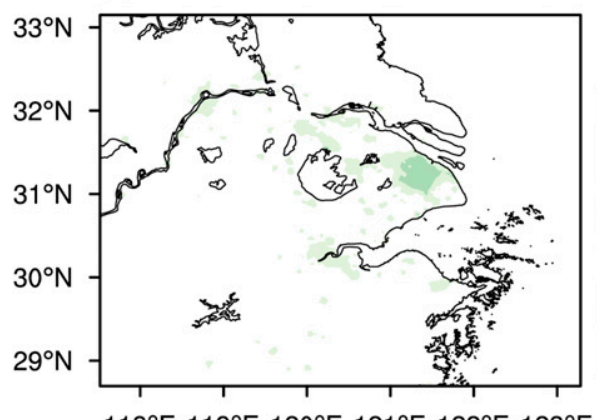

$118^{\circ} \mathrm{E} 119^{\circ} \mathrm{E} 120^{\circ} \mathrm{E} 121^{\circ} \mathrm{E} 122^{\circ} \mathrm{E} 123^{\circ} \mathrm{E}$

(e)

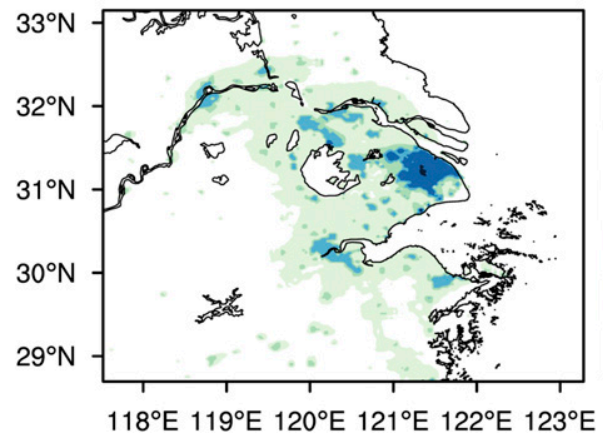

(b)
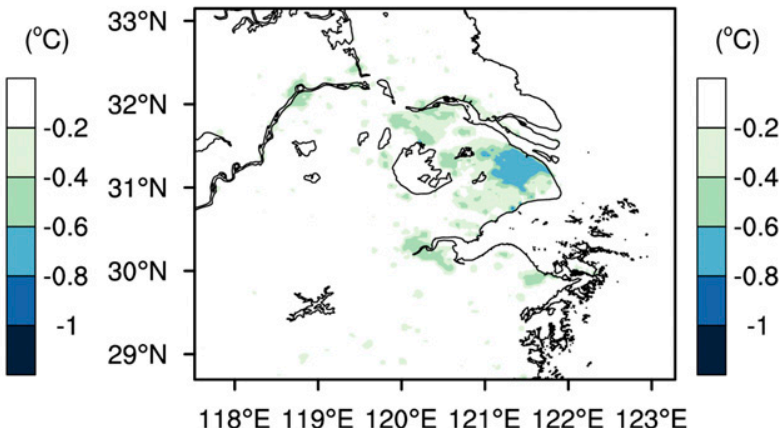

(d)

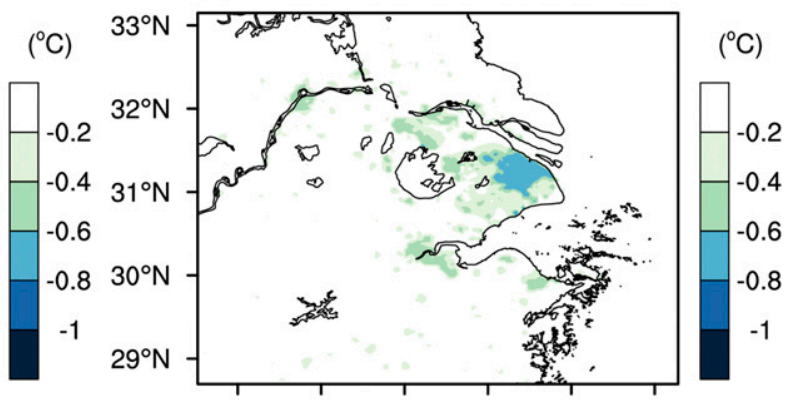

$118^{\circ} \mathrm{E} 119^{\circ} \mathrm{E} 120^{\circ} \mathrm{E} 121^{\circ} \mathrm{E} 122^{\circ} \mathrm{E} 123^{\circ} \mathrm{E}$

(f)

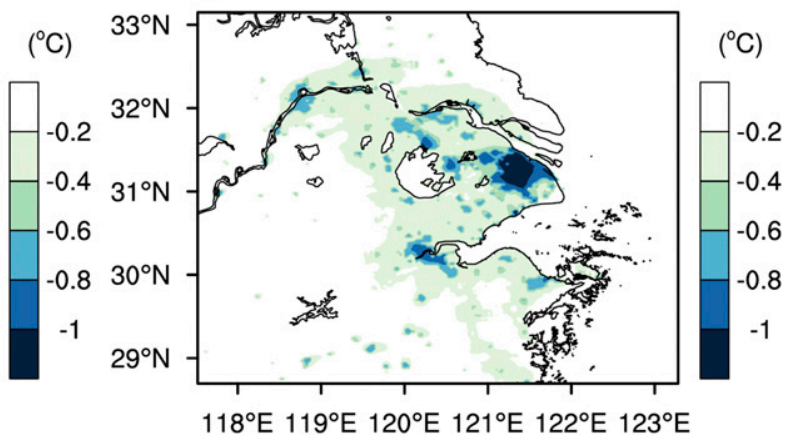

FIG. 7. Averaged differences in air temperature at $2 \mathrm{~m}$ : (a) experiment CR050 minus experiment CTL, (b) experiment CR070 minus experiment CTL, (c) experiment GR025 minus experiment CTL, (d) experiment GR050 minus experiment CTL, (e) experiment GR070 minus experiment CTL, (f) experiment GR100 minus experiment CTL.

$$
\mathrm{EI}(x)=\frac{A_{\text {change }}(x)}{A_{\text {urban }}} .
$$

Here, $x$ can be any meteorological variable. Parameter $A_{\text {change }}(x)$ is the sum of areas where $x$ changed in the sensitivity experiments compared to the CTL experiment (in this paper, the Student's $t$ test was used to calculate the significance of the changes in meteorological parameters at each model grid, and only the grids where the significance level was less than 0.05 were considered), and $A_{\text {urban }}$ is the sum of areas of cities. If EI is greater than 1 , then the mitigation has a regional impact.

\section{Results}

a. Evaluation of the simulation results of the $C T L$
experiment

The hourly air temperature at $2 \mathrm{~m} T_{2 \mathrm{~m}}$, wind speed at $10 \mathrm{~m} U_{10 \mathrm{~m}}$, and relative humidity at $2 \mathrm{~m} \mathrm{rh}_{2 \mathrm{~m}}$ observed at the 144 meteorological stations in the inner domain were compared to the WRF outputs in the CTL experiments to evaluate the model performance (Table 3 ). The CTL experiment represents this heat wave episode very well. The simulated mean $T_{2 \mathrm{~m}}$ at the 144 meteorological stations is $30.2^{\circ} \mathrm{C}$ compared with the observed 
(a)

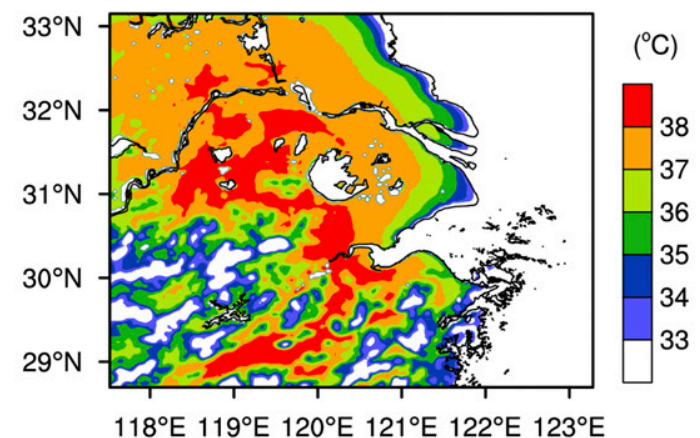

(b)

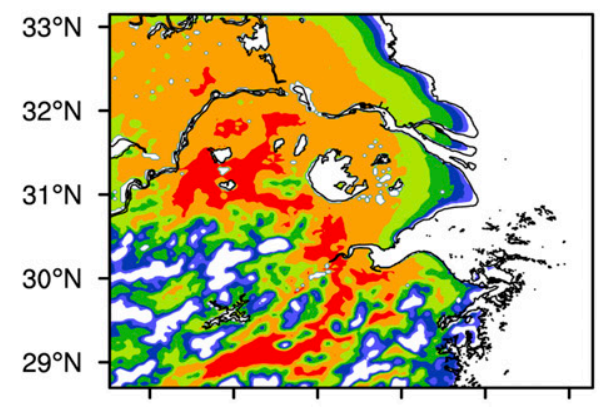

$118^{\circ} \mathrm{E} 119^{\circ} \mathrm{E} 120^{\circ} \mathrm{E} 121^{\circ} \mathrm{E} 122^{\circ} \mathrm{E} 123^{\circ} \mathrm{E}$ (d)

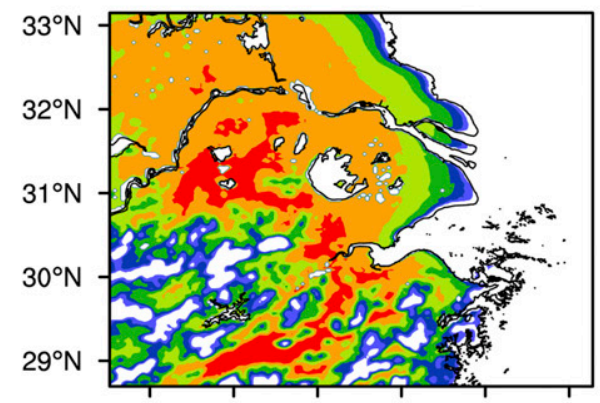

$118^{\circ} \mathrm{E} 119^{\circ} \mathrm{E} 120^{\circ} \mathrm{E} 121^{\circ} \mathrm{E} 122^{\circ} \mathrm{E} 123^{\circ} \mathrm{E}$ (f)

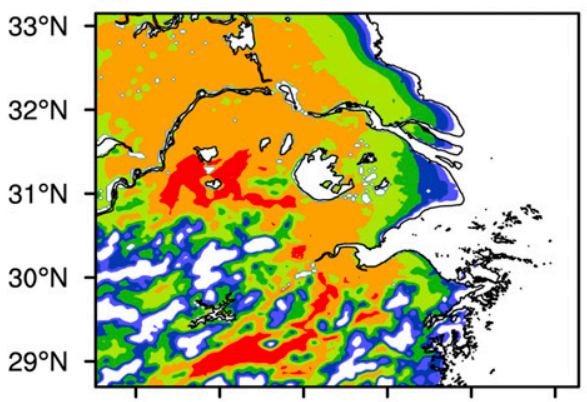

$118^{\circ} \mathrm{E} 119^{\circ} \mathrm{E} 120^{\circ} \mathrm{E} 121^{\circ} \mathrm{E} 122^{\circ} \mathrm{E} 123^{\circ} \mathrm{E}$ (c)

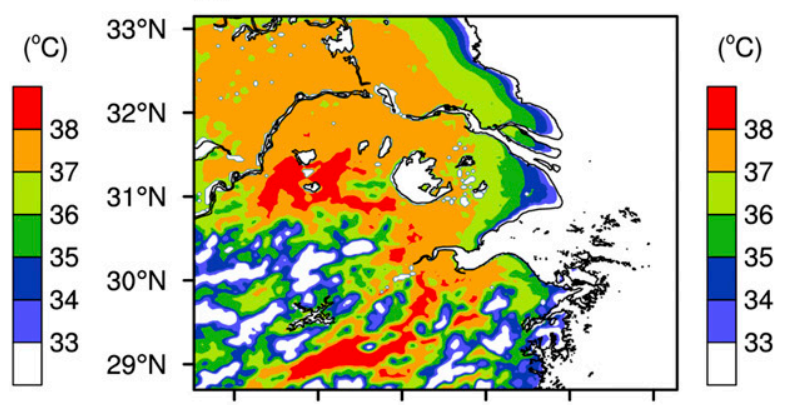

$118^{\circ} \mathrm{E} 119^{\circ} \mathrm{E} 120^{\circ} \mathrm{E} 121^{\circ} \mathrm{E} 122^{\circ} \mathrm{E} 123^{\circ} \mathrm{E}$ (e)

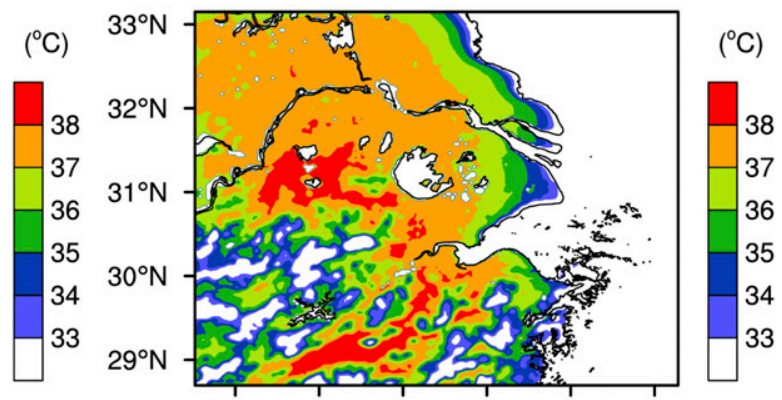

$118^{\circ} \mathrm{E} 119^{\circ} \mathrm{E} 120^{\circ} \mathrm{E} 121^{\circ} \mathrm{E} 122^{\circ} \mathrm{E} 123^{\circ} \mathrm{E}$ (g)

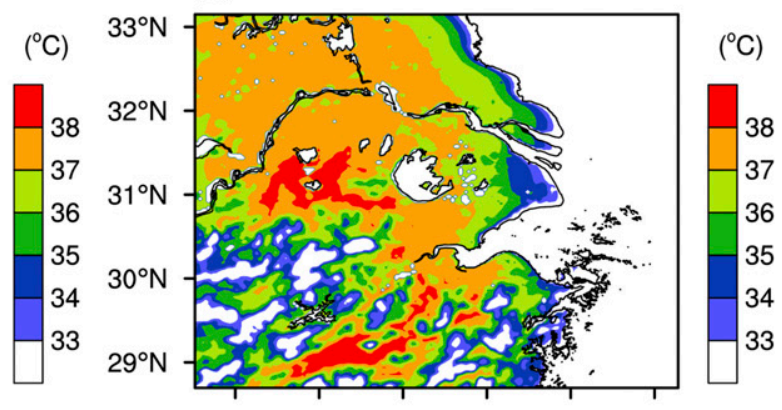

$118^{\circ} \mathrm{E} 119^{\circ} \mathrm{E} 120^{\circ} \mathrm{E} 121^{\circ} \mathrm{E} 122^{\circ} \mathrm{E} 123^{\circ} \mathrm{E}$

FIG. 8. As in Fig. 6, but for the average daily maximum temperature.

$T_{2 \mathrm{~m}}$ of $30.3^{\circ} \mathrm{C}$. The root-mean-square error (RMSE) of $T_{2 \mathrm{~m}}$ is $2.0^{\circ} \mathrm{C}$, and the relationship coefficient $R$ is 0.95 . The WRF simulations also captured the spatial patterns of the air temperature (Fig. 2). The high temperature center appeared in the southern mountainous area of Zhejiang Province, and the average temperature was over $32.0^{\circ} \mathrm{C}$. The $T_{2 \mathrm{~m}}$ in urban metropolitan areas was also higher than that in their surrounding areas, 
(a)

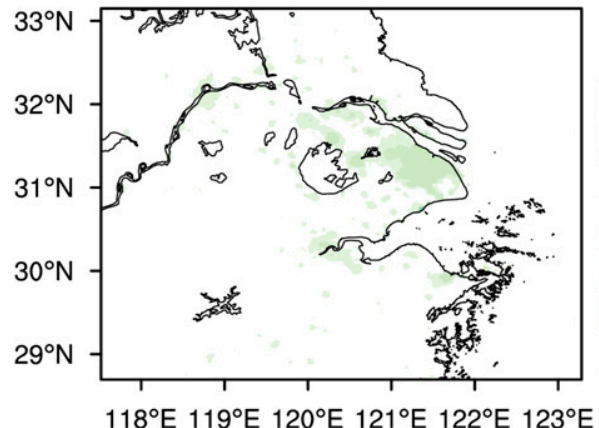

(c)

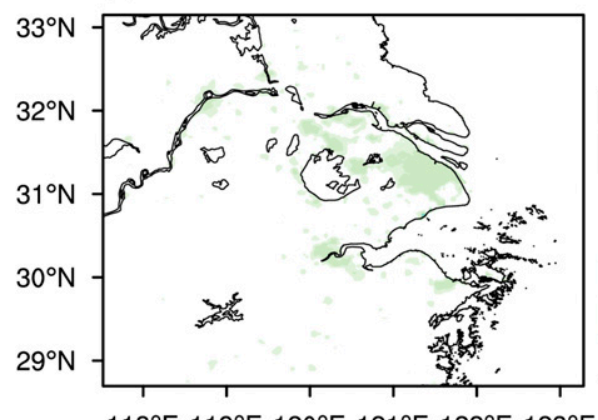

$118^{\circ} \mathrm{E} 119^{\circ} \mathrm{E} 120^{\circ} \mathrm{E} 121^{\circ} \mathrm{E} 122^{\circ} \mathrm{E} 123^{\circ} \mathrm{E}$

(e)

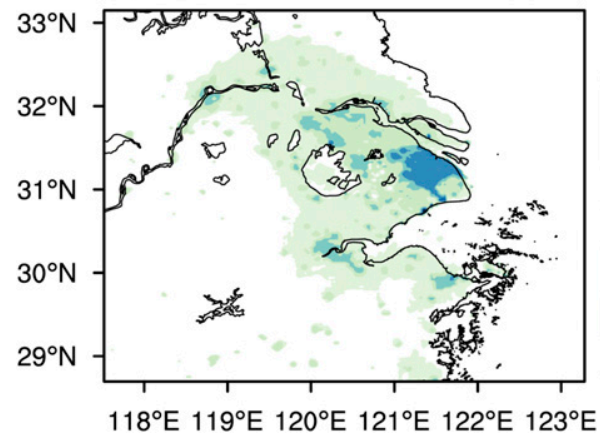

(b)
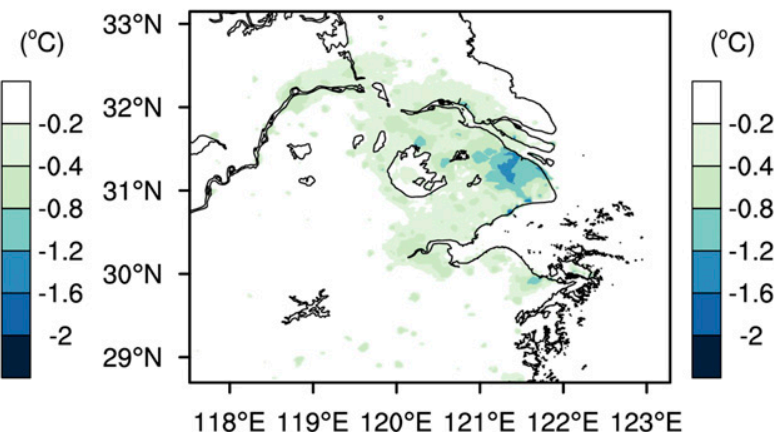

(d)

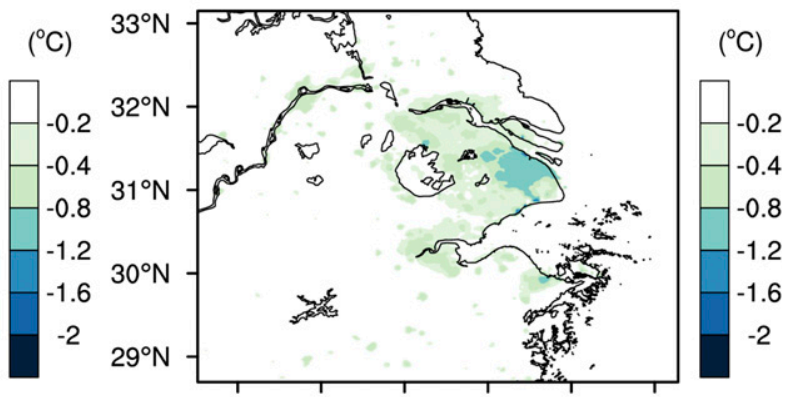

$118^{\circ} \mathrm{E} 119^{\circ} \mathrm{E} 120^{\circ} \mathrm{E} 121^{\circ} \mathrm{E} 122^{\circ} \mathrm{E} 123^{\circ} \mathrm{E}$

(f)

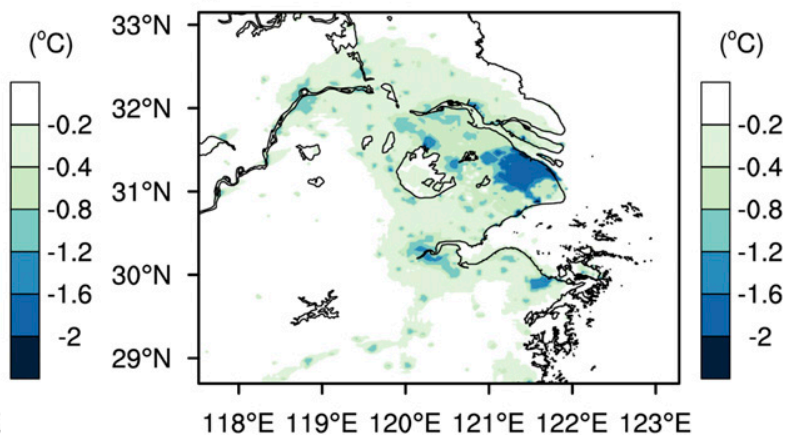

FIG. 9. As in Fig. 7, but for daily maximum air temperature at $2 \mathrm{~m}$.

showing a widely occurring UHI phenomenon. The simulations of $T_{2 \mathrm{~m}}$ performed well over both urban and rural sites with $R$ values of 0.95 and 0.96 and RMSEs of $1.9^{\circ}$ and $2.0^{\circ} \mathrm{C}$, respectively.

The WRF-simulated $\mathrm{rh}_{2 \mathrm{~m}}$ is $61.4 \%$, which is less than the station-observed average $(68 \%)$, with a mean bias (MB) of $-6.8 \%$. The $R$ of $\mathrm{rh}_{2 \mathrm{~m}}$ is 0.80 , and the RMSE is $6.8 \%$. The model underestimated $\mathrm{rh}_{2 \mathrm{~m}}$, with a bias of $-9.7 \%$ over urban sites and a bias of $-5.0 \%$ over rural sites; the RMSEs are $7.8 \%$ and $5.5 \%$, respectively. Unlike in previous simulations of summer climatology over this area (Zhang et al. 2010) and the studies over other urban clusters in China (Barlage et al. 2016), the model underestimated the wind speed at the height of $10 \mathrm{~m}$. The station-observed average is $2.4 \mathrm{~m} \mathrm{~s}^{-1}$, while the WRF-simulated average is $1.8 \mathrm{~m} \mathrm{~s}^{-1}$, the RMSE is $0.89 \mathrm{~m} \mathrm{~s}^{-1}$, and the $R$ is 0.72 . The underestimation of surface wind speed mostly occurred over rural sites, the simulation bias is $-0.7 \mathrm{~m} \mathrm{~s}^{-1}$, the $R$ is 0.69 , and the RMSE is $1.0 \mathrm{~m} \mathrm{~s}^{-1}$.

The simulated surface skin temperature (TSK) in the CTL experiment was compared to the $0.05^{\circ}$ MODISobserved results [Global monthly MODIS/Terra Land Surface Temperature data (MOD11C3)]) as shown in Fig. 3. During this summer, the MODIS-observed season (JJA) averaged daytime (the MODIS observation time is approximately $1330 \mathrm{LT}$ ) TSK over urban areas is above $38^{\circ} \mathrm{C}$, and the nighttime (the observation time is approximately $0130 \mathrm{LT}$ ) mean TSK is above $28^{\circ} \mathrm{C}$. The WRF Model-simulated spatially averaged daytime TSK 
(a)

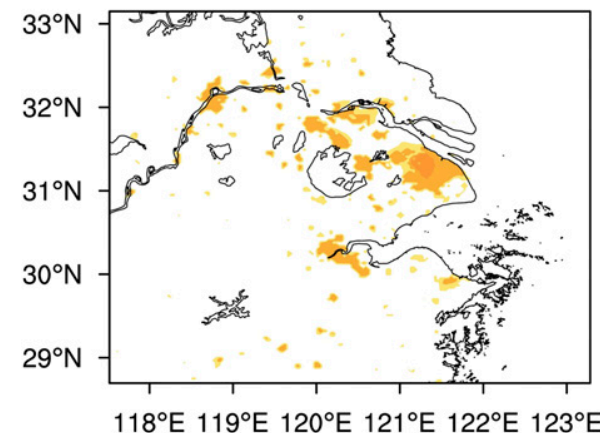

(c)

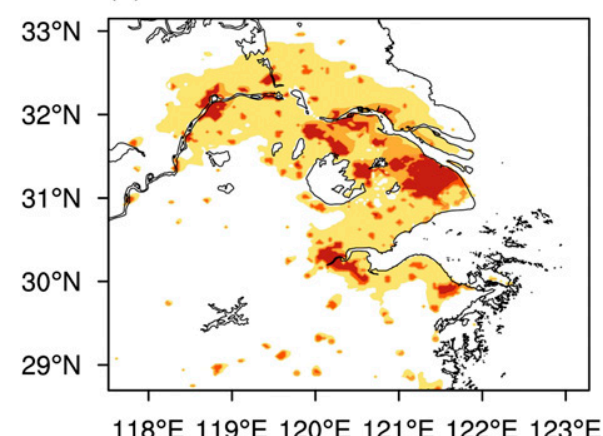

(b)
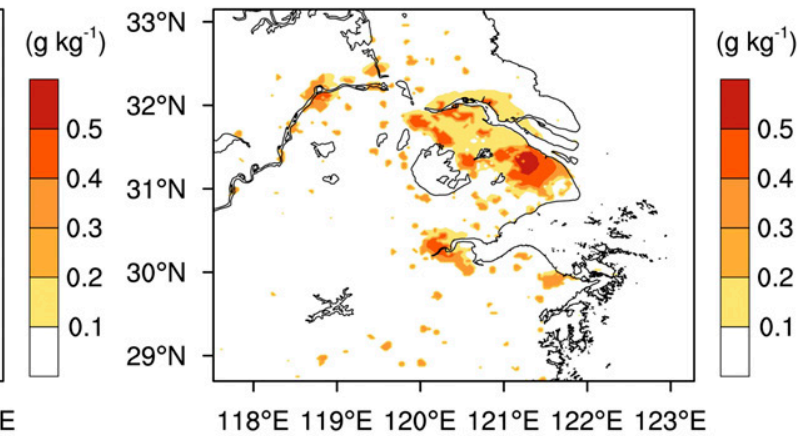

(d)
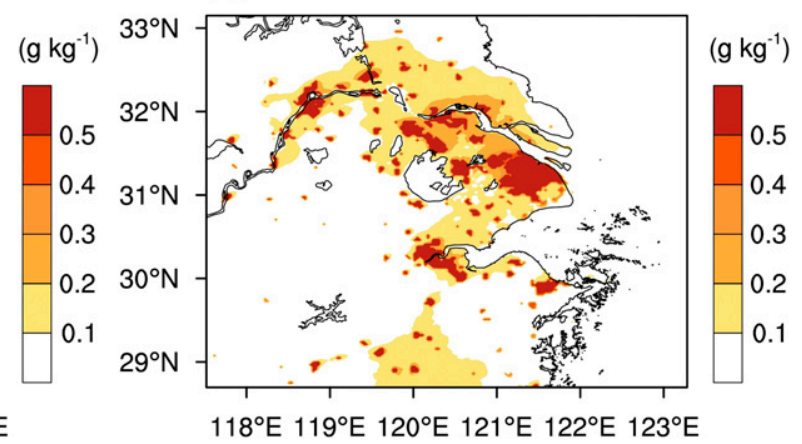

FIG. 10. Season averaged differences in specific humidity at $2 \mathrm{~m}$ : (a) experiment GR025 minus experiment CTL, (b) experiment GR050 minus experiment CTL, (c) experiment GR070 minus experiment CTL, and (d) experiment GR100 minus experiment CTL

is $35.5^{\circ} \mathrm{C}$ compared with the MODIS observation of $33.1^{\circ} \mathrm{C}$; the model overestimated the daytime TSK with a bias of approximately $2.4^{\circ} \mathrm{C}$, and most of the errors occurred in the north part of the inner domain. The simulated spatial nighttime TSK is $25.5^{\circ} \mathrm{C}$ and the MODIS observation is $25.6^{\circ} \mathrm{C}$, while an underestimation of about $-1.0^{\circ} \mathrm{C}$ appeared in the southwest area of the inner domain and an overestimation about $1.5^{\circ}-2.0^{\circ} \mathrm{C}$ appeared over the urban area. The simulated distribution patterns of daytime and nighttime TSK agree well with MODIS observations; both the observations and simulations show a higher TSK over urban areas, which indicates that urbanization plays an important role in this hot summer, as discussed in J. Wang et al. (2016), and the mitigation of the urban heat island will help reduce the impact of the heat wave.

\section{b. Mitigation effectiveness of cool and green roofs in urban areas}

Both cool roofs and green roofs reduce the urban heat island by changing the surface radiation budget and surface energy budget over urban areas. Figure 4 illustrates the changes in the surface sensible heat flux and latent heat flux over urban areas in different sensitivity experiments compared with the CTL experiment (the results of sensitivity experiments minus the results of the CTL experiment). In all the sensitivity experiments, the surface sensible heat flux decreases with an increase in roof albedo or an increase in the green roof fraction. The peak of the decrease occurred at nearly noon, and the values were $-102.1,-169.0,-103.2,-154.2,-194.5$, and $-254.8 \mathrm{Wm}^{-2}$ in the CR050, CR070, GR025, GR050, GR070, and GR100 experiments, respectively. Cool roofs have little impact on the surface latent heat flux over urban areas, while green roofs increase the surface latent heat flux over urban areas by adding additional moisture from the evapotranspiration of plants and irrigation. The increase in latent heat flux was 106.8, 154.1, 190.3, and $246.1 \mathrm{~W} \mathrm{~m}^{-2}$ in the GR025, GR050, GR070, and GR100 experiments, respectively. Cool roofs mitigate the urban heat island mainly by decreasing the solar radiation absorbed by urban surfaces, so the surface net radiation also decreases in the daytime; the peaks of the decrease occurred at noon as well, and the value was $-102.2 \mathrm{~W} \mathrm{~m}^{-2}$ in the CR050 experiment and $-196.8 \mathrm{~W} \mathrm{~m}^{-2}$ in the CR070 experiment. The change in net radiation was very close to the change in surface sensible heat flux. The impact of green roofs on the surface net radiation is relatively slight, but it changes the surface energy partition between the 
(a)

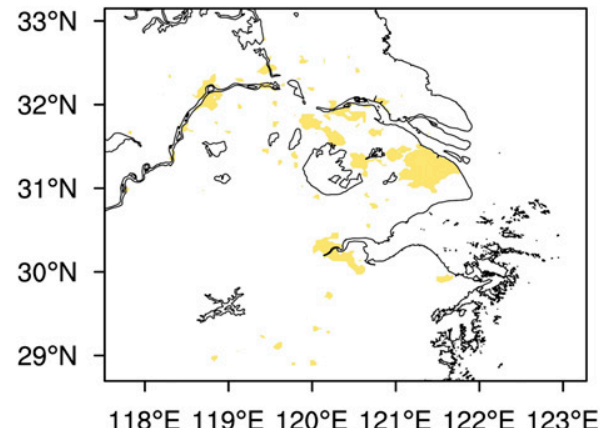

(c)

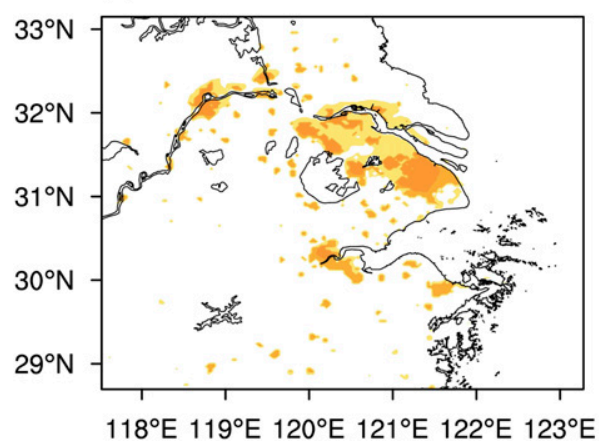

(b)
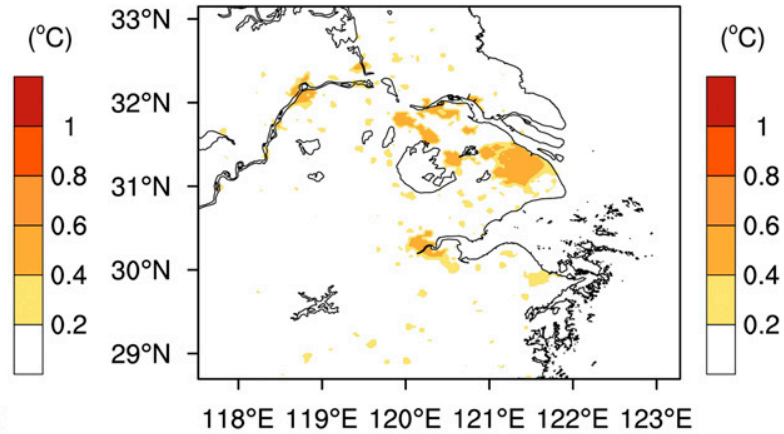

(d)
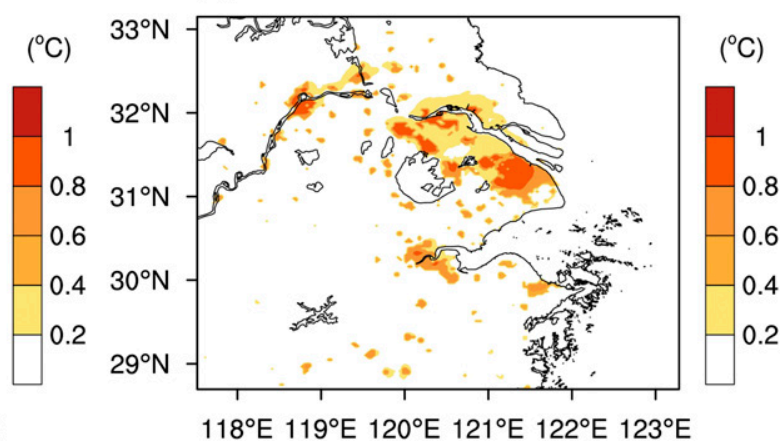

FIG. 11. As in Fig. 10, but for dewpoint temperature at $2 \mathrm{~m}$.

sensible heat flux and latent heat flux. The surface energy partition changes from sensible heat flux dominated to latent heat flux dominated when the green fraction is greater than $50 \%$ in our experiments.

Both cool roofs and green roofs were proven to be effective methods for urban heat island mitigation in this hot summer, and both the TSK and $T_{2 \mathrm{~m}}$ decreased with the increase in roof albedo or the green roof fraction (Fig. 5). The daily mean decreases of the simulated TSK were $-1.4^{\circ},-2.4^{\circ},-1.6^{\circ},-2.4^{\circ},-3.0^{\circ}$, and $-3.8^{\circ} \mathrm{C}$ in the CR050, CR070, GR025, GR050, GR070, and GR100 experiments, respectively, and the daily mean decreases in $T_{2 \mathrm{~m}}$ were $-0.2^{\circ},-0.4^{\circ},-0.3^{\circ},-0.5^{\circ},-0.7^{\circ}$, and $-1.0^{\circ} \mathrm{C}$ in the CR050, CR070, GR025, GR050, GR070, and GR100 experiments, respectively. The maximum decrease in TSK occurred at noon, and the maximum decrease of the air temperature at $2 \mathrm{~m} \mathrm{oc}$ curred in the early afternoon in all sensitivity experiments. The daily maximum decreases in the simulated TSK were $-3.4^{\circ},-5.9^{\circ},-3.5^{\circ},-5.4^{\circ},-7.0^{\circ}$, and $-9.4^{\circ} \mathrm{C}$ in the CR050, CR070, GR025, GR050, GR070, and GR100 experiments, respectively, and those of air temperature were $-0.4^{\circ},-0.8^{\circ},-0.4^{\circ},-0.7^{\circ},-1.0^{\circ}$, and $-1.3^{\circ} \mathrm{C}$, respectively. Our results also showed that cool roofs with an albedo of 0.5 (0.7) have similar effectiveness as green roofs at a fraction of $25 \%(50 \%)$, which is close to the results in the Baltimore-Washington metropolitan area (Li et al. 2014). Green roofs can also increase the near-surface humidity by increasing the surface evapotranspiration. The daily mean specific humidity at $2 \mathrm{~m}\left(q_{2 \mathrm{~m}}\right)$ over the urban area increased $0.2,0.3,0.4$, and $0.6 \mathrm{~g} \mathrm{~kg}^{-1}$ as the green roof fraction increased from $25 \%$ to $100 \%$; at the same time, the daily mean $\mathrm{rh}_{2 \mathrm{~m}}$ increased by $1.5 \%, 2.4 \%, 3.5 \%$, and $4.0 \%$ in the respective sensitivity experiments. The maximum increase of specific humidity was $0.4,0.6,0.9$, and $1.2 \mathrm{~g} \mathrm{~kg}^{-1}$ in the GR025, GR050, GR070, and GR100 experiments, respectively, and the maximum change of $\mathrm{rh}_{2 \mathrm{~m}}$ was $2.4 \%, 3.8 \%, 5.3 \%$, and $6.9 \%$, respectively. Cool roofs had little influence on the near-surface humidity, but the decrease in the near-surface air temperature also caused the increase of the near-surface relative humidity over urban areas. The average and maximum increases in $\mathrm{rh}_{2 \mathrm{~m}}$ were, respectively, $0.7 \%$ and $1.2 \%$ in the CR050 experiment and $1.5 \%$ and $2.4 \%$ in the CR070 experiment. The changes of the dewpoint temperature in the cool roof experiments are negligible while the green roofs caused increases of the dewpoint temperature at $2 \mathrm{~m}$, and the maximum values were $0.4^{\circ}$, $0.6^{\circ}, 0.8^{\circ}$, and $1.2^{\circ} \mathrm{C}$ in the GR025, GR050, GR070, and GR100 experiments, respectively. Unlike previous studies in some North American cities (Sharma et al. 2016), the impacts of green roofs and cool roofs on the near-surface wind are very slight in our simulations; only 
(a)

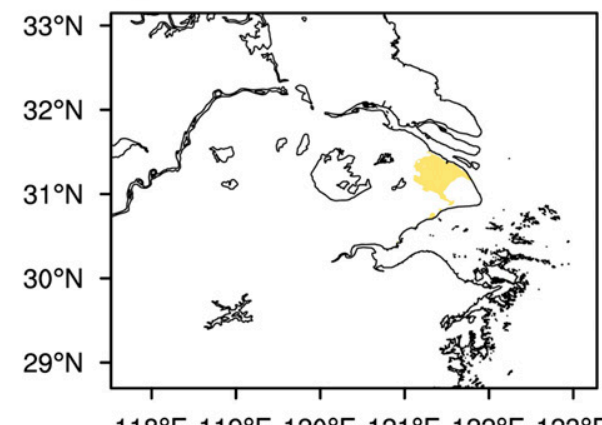

(c)

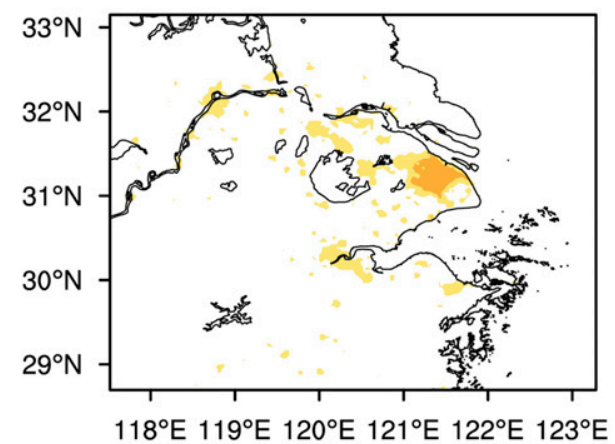

(e)

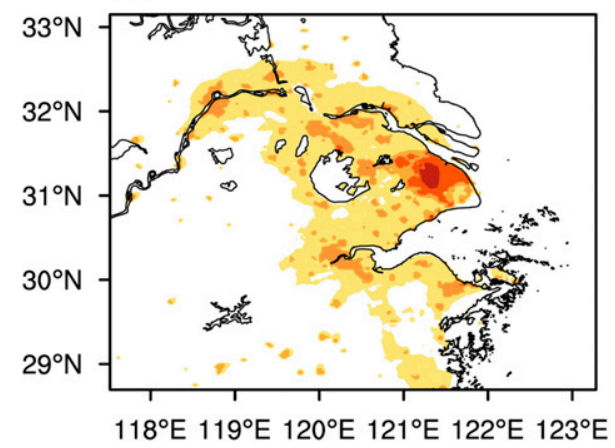

(b)
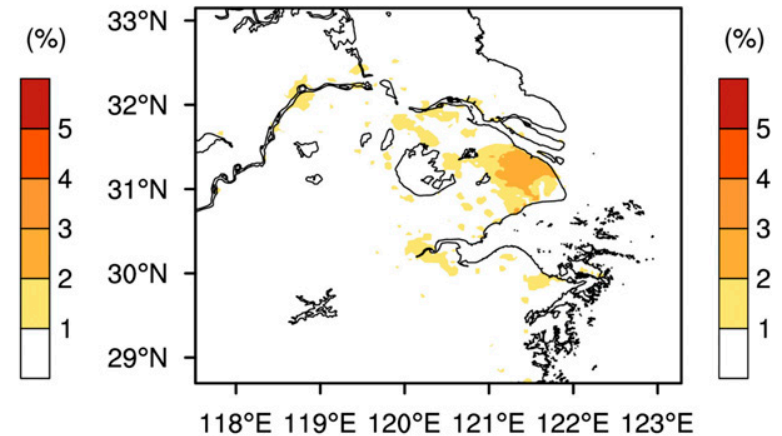

(d)
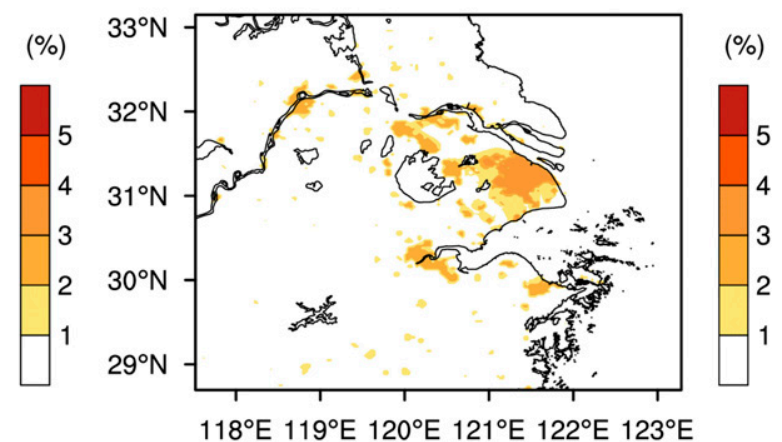

(f)
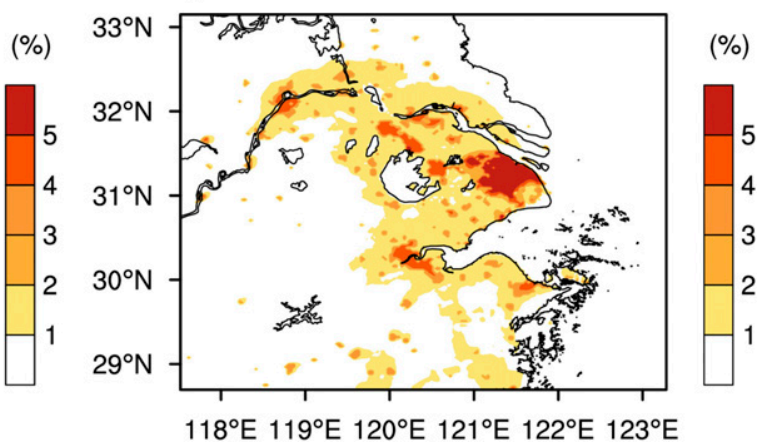

FIG. 12. As in Fig. 7, but for relative humidity at $2 \mathrm{~m}$.

the GR100 experiments showed weak decreases in wind speed at $10 \mathrm{~m}$. The impacts on the boundary layer wind fields will be discussed in section $2 \mathrm{~d}$.

\section{c. Regional impact on surface meteorological fields}

EIs in surface air temperature, humidity, dewpoint temperature, and wind speed were used to observe the regional impacts of different UHI mitigation strategies (Table 4). Differences in the seasonal averaged $T_{2 \mathrm{~m}}$ between the sensitivity experiments and the CTL experiment showed that in most of the sensitivity experiments, the cool roof or green roof had a regional influence. Only in the CR050 and GR025 experiments are the EIs of $T_{2 \mathrm{~m}}$ less than 1 , with values of 0.68 and 0.90 , respectively. In the GR070 and GR100 experiments, the mitigation strategy caused a
$T_{2 \mathrm{~m}}$ decrease of $0.15^{\circ} \mathrm{C}$ in the whole inner domain (Figs. 6 and 7). The EIs in the GR070 experiment and the GR100 experiment are very close, even though the mitigation caused stronger air temperature decreases in the GR100 experiment. The changes in daily maximum $T_{2 \mathrm{~m}}$ have similar patterns as the changes in daily mean $T_{2 \mathrm{~m}}$ but have greater absolute values as shown in Figs. 8 and 9; and the simulations also showed that regional impacts happened in the GR050, GR070, GR100, and CR050 experiments.

Green roofs supply urban areas with additional evapotranspiration, and this impact shows a regional effect in all the green roof experiments. In all green roof experiments, the EIs of $q_{2 \mathrm{~m}}$ are greater than 1 , and in the GR070 and GR100 experiments (Fig. 10), the high fraction of green roofs caused an increase of 0.06 and 
(a)

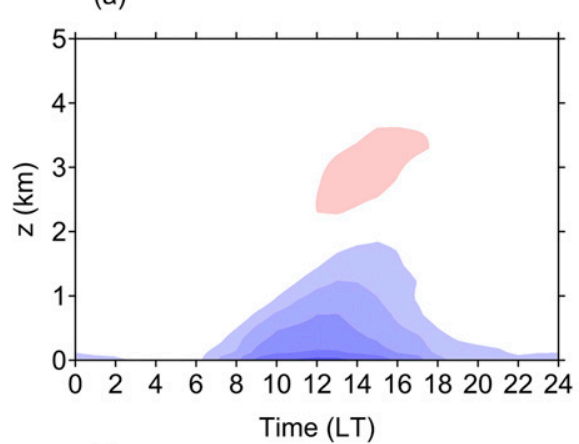

(c)

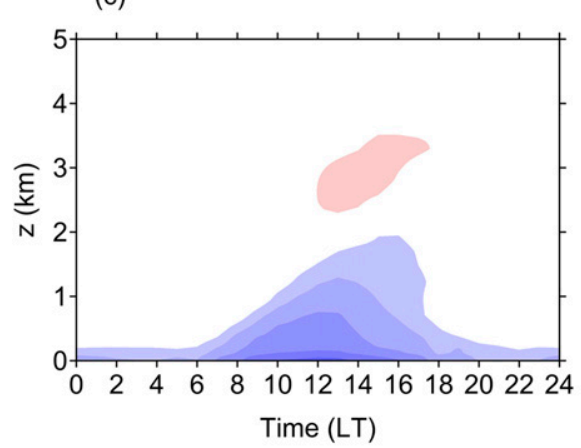

(e)
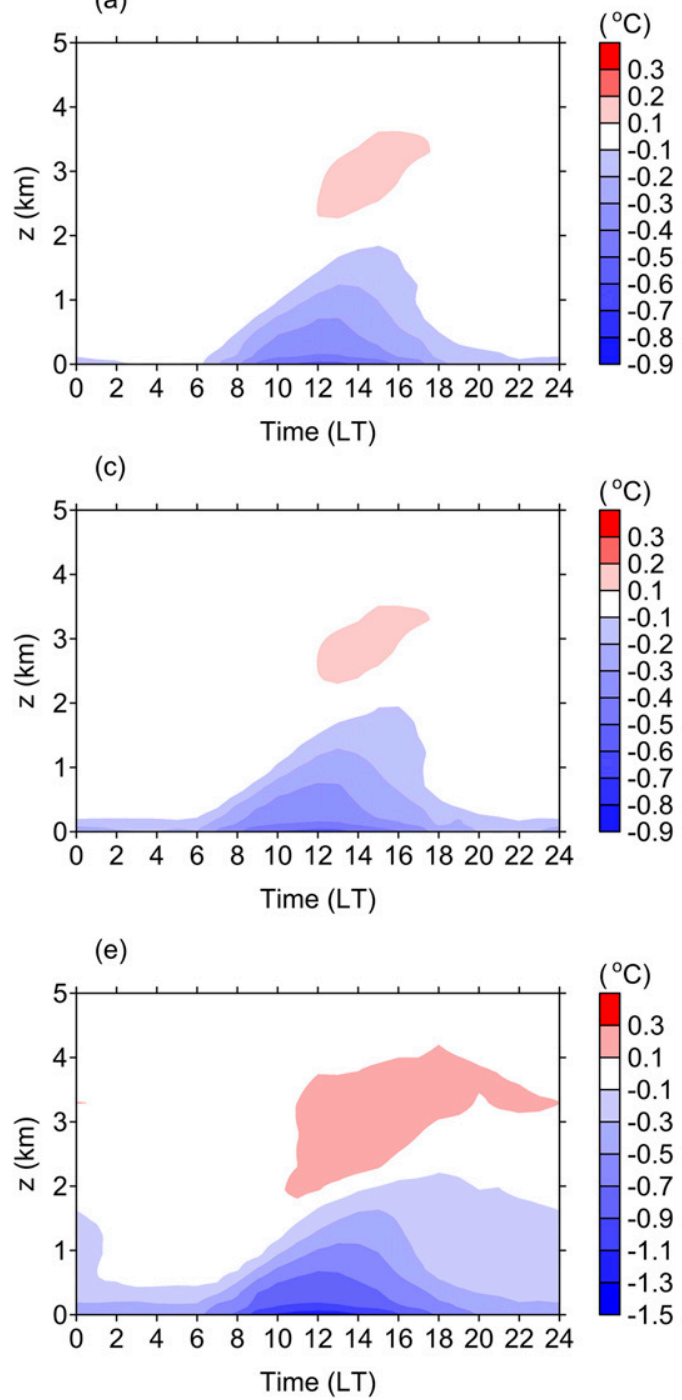

(b)

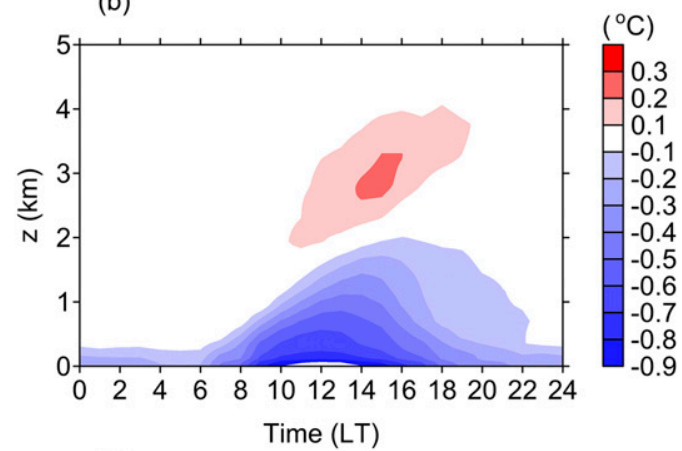

(d)

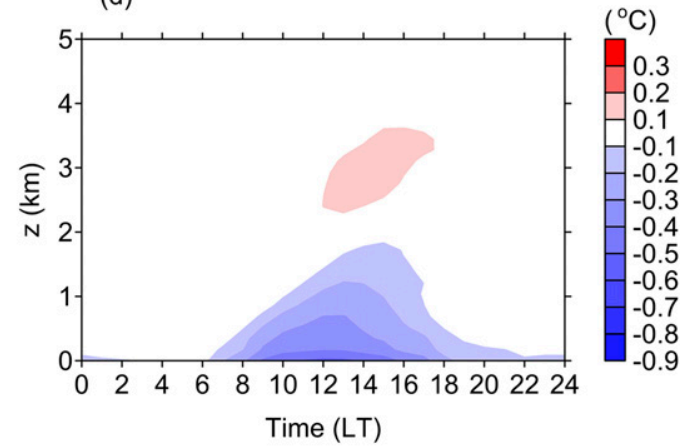

(f)

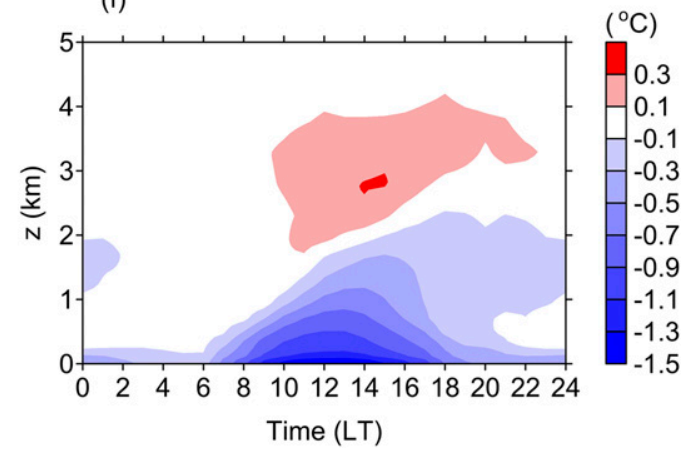

FIG. 13. Averaged vertical differences in air temperature: (a) experiment CR050 minus experiment CTL, (b) experiment CR070 minus experiment CTL, (c) experiment GR025 minus experiment CTL, (d) experiment GR050 minus experiment CTL, (e) experiment GR070 minus experiment CTL, and (f) experiment GR100 minus experiment CTL.

$0.07 \mathrm{~g} \mathrm{~kg}^{-1}$ in $q_{2 \mathrm{~m}}$ over the whole domain. The increases in $q_{2 \mathrm{~m}}$ also led to increases in dewpoint temperature at $2 \mathrm{~m}$ in the green roof experiments (Fig. 11), especially over the urban areas, where the maximum increase in dewpoint temperature at $2 \mathrm{~m}$ reached $0.83^{\circ} \mathrm{C}$ in the GR100 experiments; the changes in the near-surface dewpoint temperature are negligible in the CR050 and CR070 experiments. By impacting $T_{2 \mathrm{~m}}$ and $q_{2 \mathrm{~m}}$, both cool roofs and green roofs also modified the nearsurface relative humidity in all sensitivity experiments (Fig. 12). The EI of $\mathrm{rh}_{2 \mathrm{~m}}$ in the CR050 experiments is 0.18 , which indicates that the changes in $q_{2 \mathrm{~m}}$ only occurred in a small part of the urban area. The EIs of $\mathrm{rh}_{2 \mathrm{~m}}$ in CR070 and GR025 are close to 1, which means that the impacts only occurred over urban areas. The GR050,
GR070, and GR100 experiments showed strong regional effect on $\mathrm{rh}_{2 \mathrm{~m}}$ with EI values of 1.34, 4.53, and 4.53, respectively. The EIs of the dewpoint temperature at $2 \mathrm{~m}$ are close to these of $\mathrm{rh}_{2 \mathrm{~m}}$ in the sensitivity experiments.

\section{d. Impacts on atmospheric boundary layer structure and precipitation}

The mitigation of the urban heat island not only changes near-surface meteorological conditions but also can modify the structure of the local boundary layer (Sharma et al. 2016). The simulated vertical profiles of air temperature, specific/relative humidity, and vertical wind speed over urban grids in the inner domain were averaged to observe the impacts on atmospheric boundary layer structure. The results in our simulations 
(a)

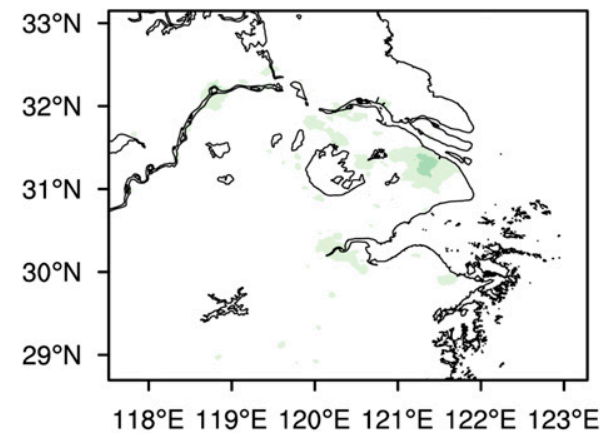

(c)

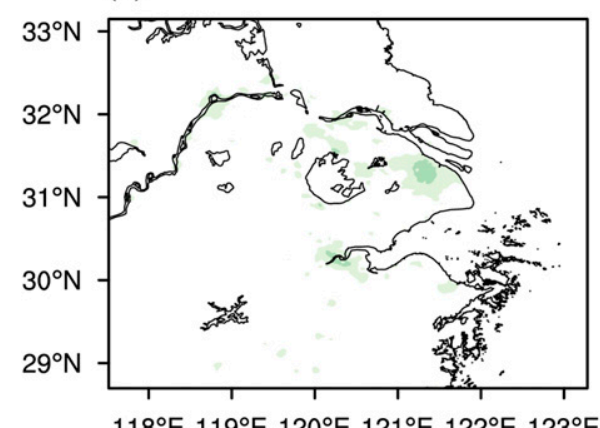

(e)
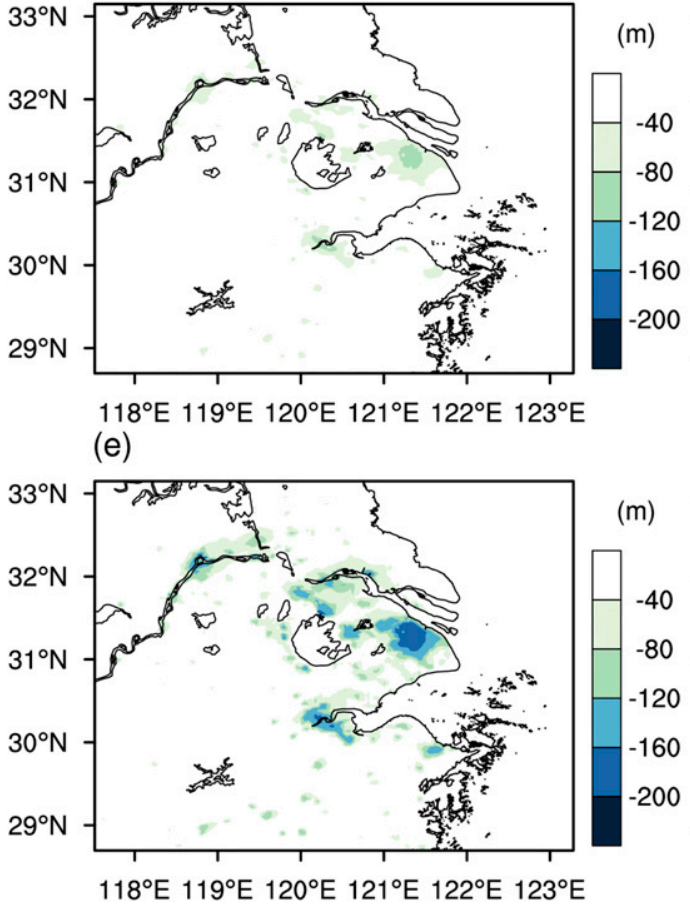

(b)

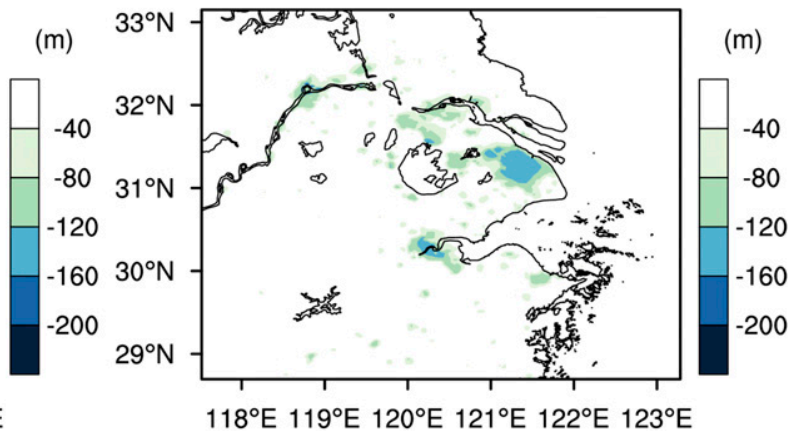

(d)

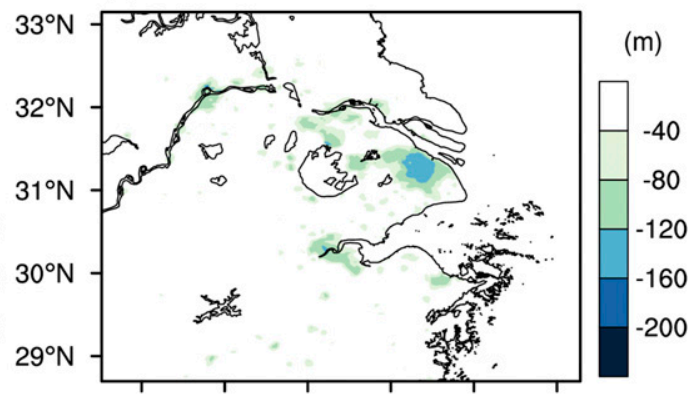

$118^{\circ} \mathrm{E} 119^{\circ} \mathrm{E} 120^{\circ} \mathrm{E} 121^{\circ} \mathrm{E} 122^{\circ} \mathrm{E} 123^{\circ} \mathrm{E}$

(f)

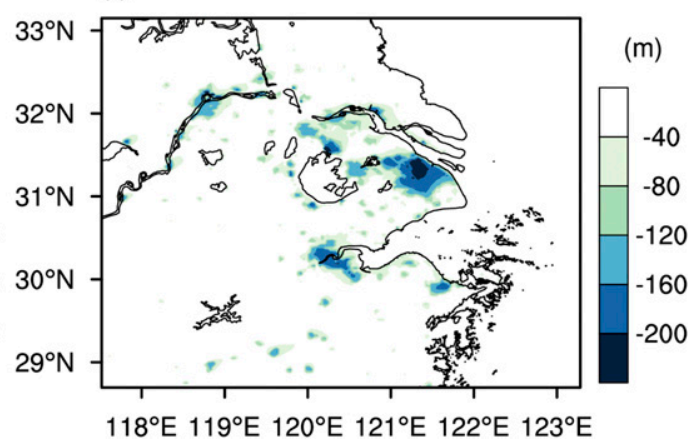

FIG. 14. As in Fig. 7, but for the atmospheric boundary layer height.

show that both cool roofs and green roofs will modify the atmospheric boundary layer structure over urban areas, especially in daytime, when the effectiveness of mitigation is significant. The decrease in air temperature extended from the urban surface to approximately $0.1 \mathrm{~km}$ at night and reached nearly $2.0 \mathrm{~km}$ at noon (Fig. 13). At the same time, increases in air temperature above the boundary layer were observed in all sensitivity experiments; such a phenomenon is similar to what happened in previous numerical simulations and observations of the urban heat island, where the warming and drying effects of cities are reversed near the top of the atmospheric boundary layer (Bornstein 1968; Sparks and Toumi 2015). This kind of "crossover"-like effect also occurred in the results of Sharma et al. (2016). Compared to the decreases in surface temperature caused by green roofs and cool roofs, the temperature increases above the top of the boundary layer are relatively weak, only approximately $0.1^{\circ}-0.3^{\circ} \mathrm{C}$ at noon in different experiments; the changes in the vertical profiles of temperature enhanced the inversion layer above the boundary layer and increased the stratification of the urban boundary layer. This resulted in the decrease of the planetary boundary layer height (PBLH); the seasonal averaged decrease of the model-diagnosed PBLH could reach more than $150 \mathrm{~m}$ over the urban area (Fig. 14). The impact of the PBLH also has a regional effect; the regional EIs of the PBLH in the CR050, CR070, GR025, GR050, GR070, and GR100 experiments were 1.49, $3.001 .66,2.40,5.20$, and 5.10, respectively (Table 4). 
(a)

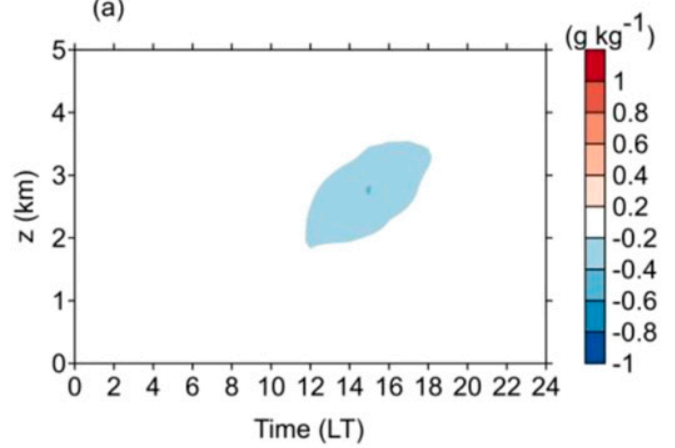

(c)

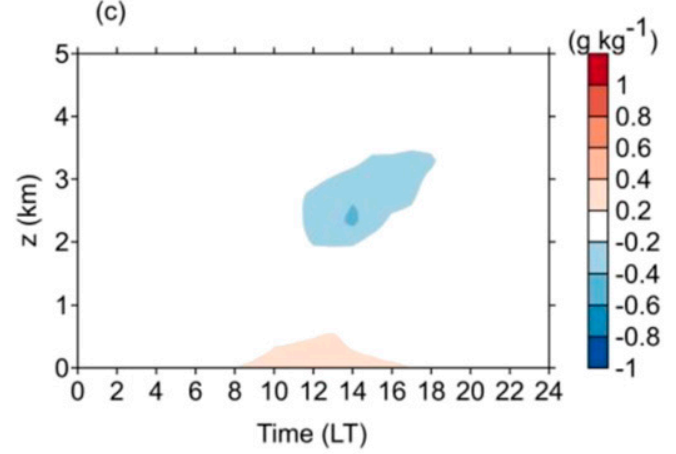

(e)

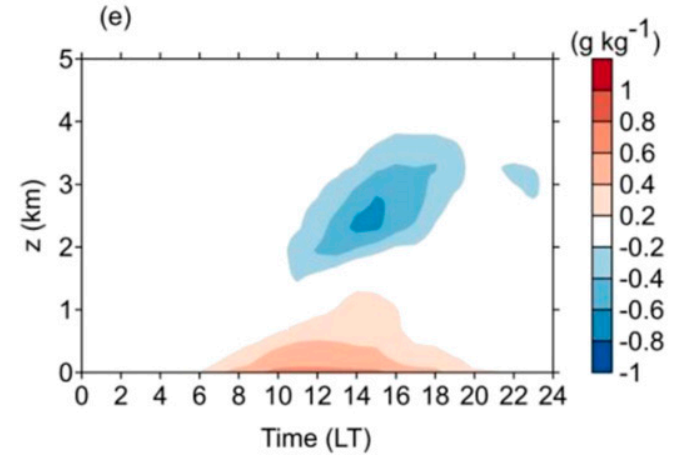

(b)

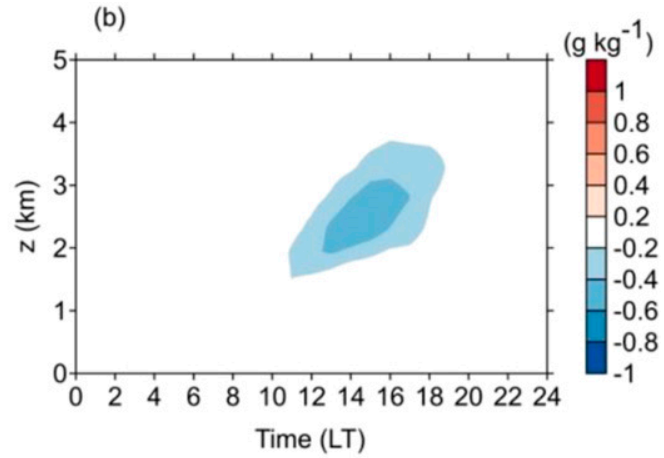

(d)
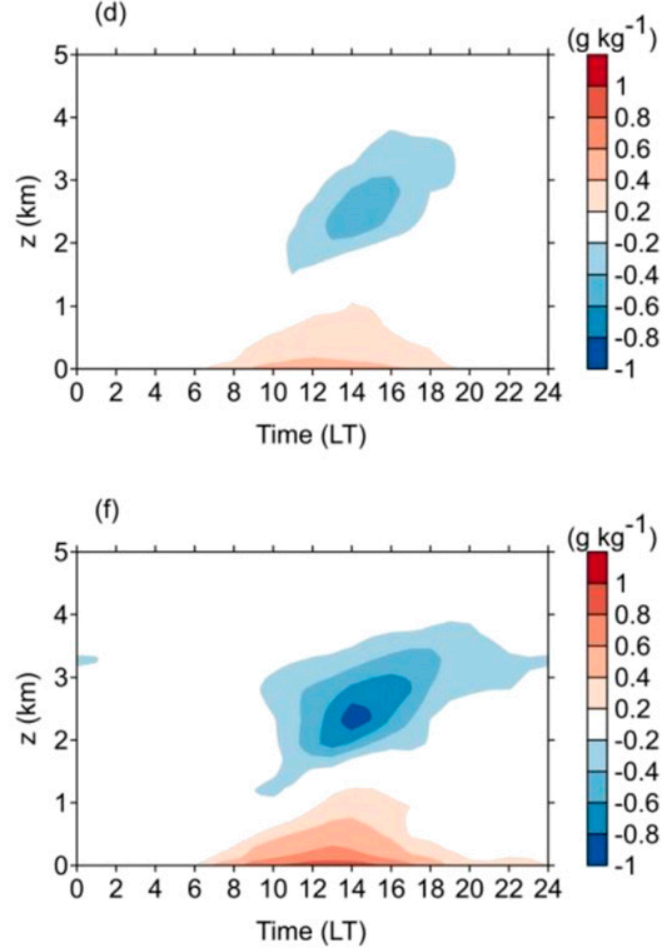

FIG. 15. As in Fig. 13, but for specific humidity.

This kind of crossover effect can also be observed in the differences in specific humidity and relative humidity. Increases in the specific humidity in the boundary layer and decreases in the specific humidity above the boundary layer occurred in all the green roof experiments (Figs. 15c-f). The increase in the near-surface specific humidity could be greater than $0.8 \mathrm{~g} \mathrm{~kg}^{-1}$, and the decrease in the specific humidity above the boundary layer could reach $1.0 \mathrm{~g} \mathrm{~kg}^{-1}$ in the GR100 experiments. In the cool roof experiments, the increase in the specific humidity in the boundary layer did not occur, but the crossover effects of the specific humidity above the boundary layer were still observed in the afternoon (approximately 1100-1800 LT in the CR070 experiment), as shown in Figs. 15a-b. Under the combined impact of changes in the specific humidity and air temperature, both the increase in the relative humidity of the boundary layer and the decrease of the relative humidity above the boundary layer occurred in all the sensitivity experiments (Fig. 16). The increase in the near-surface relative humidity could be greater than $5 \%$, and the decrease in the relative humidity above the boundary layer could reach 7\% in the GR100 experiments. The reason for such a crossover effect is the decrease in the air temperature of the boundary layer under the mitigation strategies of the urban heat island. As discussed in section 3a, both cool and green roofs decreased the surface sensible heat flux and generated a more stable atmospheric boundary layer. The decrease in the air temperature also reduced the vertical wind speeds (Fig. 17). The maximum decrease in the vertical wind speed reached approximately $4.0 \mathrm{~cm} \mathrm{~s}^{-1}$ in the 
(a)

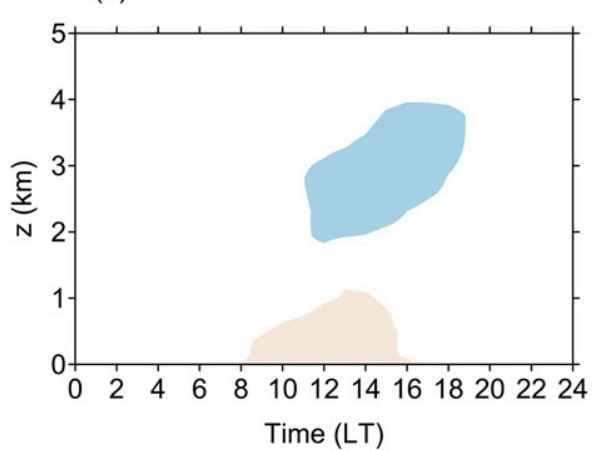

(c)

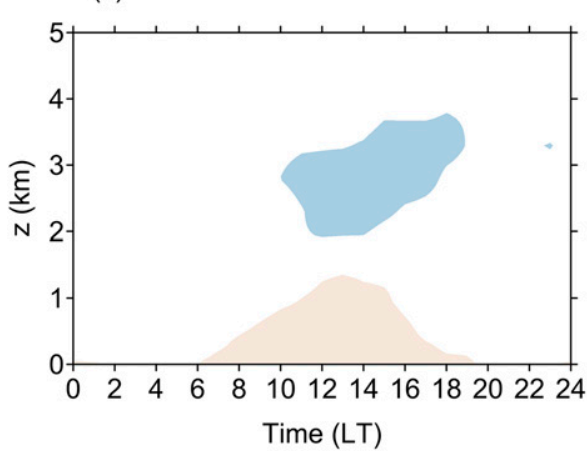

(e)

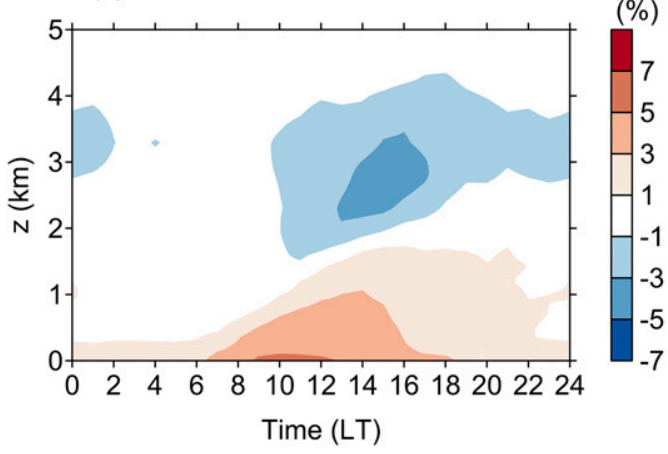

(b)

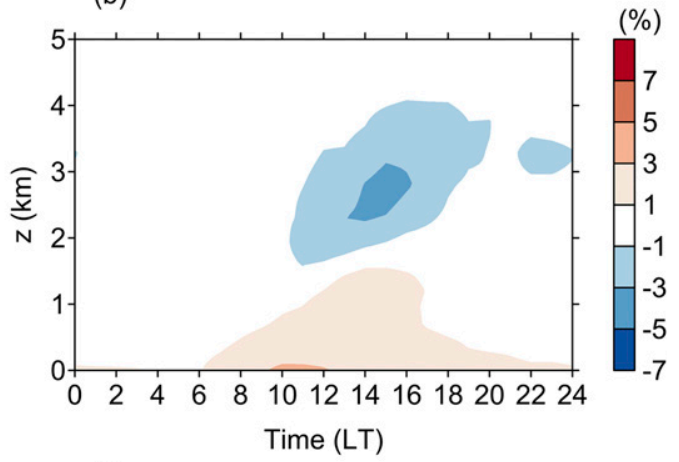

(d)

(\%)

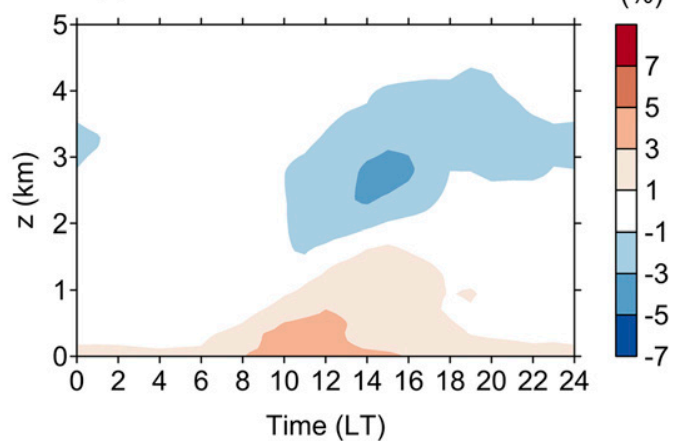

(f)

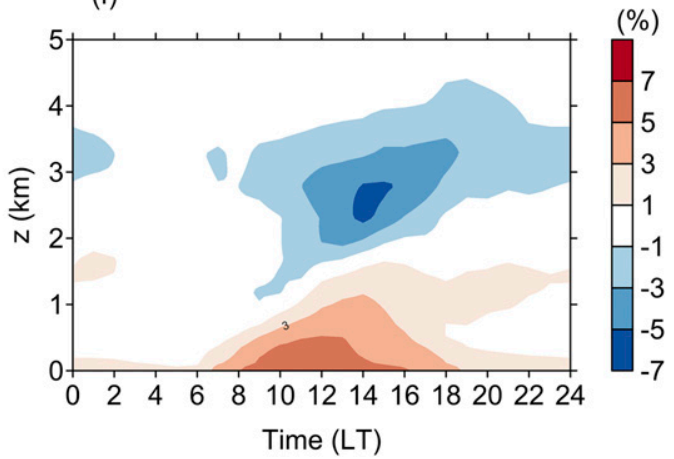

FIG. 16. As in Fig. 13, but for relative humidity.

CR050 and GR025 experiments and reached approximately $8.0 \mathrm{~cm} \mathrm{~s}^{-1}$ in the GR100 experiment; the decreases only were observed in the daytime and peaked around 1500 LST. The decrease in the vertical wind speed reduced the vertical transport of moisture and caused a wetter atmospheric boundary layer and a drier air layer above.

Previous studies have documented that UHI is among the main ways that urbanization influences precipitation (Shepherd 2005; Trusilova et al. 2008; Zhang et al. 2010). Zhang et al. (2010) found that the urbanization in the Yangtze River delta caused an urban heat island circulation and increased the precipitation over the major cities by about $15 \%$ in summer. But the simulations in this paper showed that the UHI mitigation strategies had little influence on the summer precipitation in 2013; the change ratios of season total precipitation in the sensitivity experiments are less than $0.5 \%$ compared with the CTL experiments (Fig. 18). The changes in the spatial pattern of precipitation were mostly caused by the sensitivities of convection and microphysical parameterization schemes to the land surface changes and did not pass the significance test. The potential reason is that the summer of 2013 was a relatively dry summer compared with the climatological average because of the month-long (July and the first half of August) heat wave episode. In June, the precipitation in the Yangtze River delta is usually controlled by the mei-yu (tsuyu) front, and the UHI mitigation impacts might be negligible compared to the strong synoptic background. 
(a)

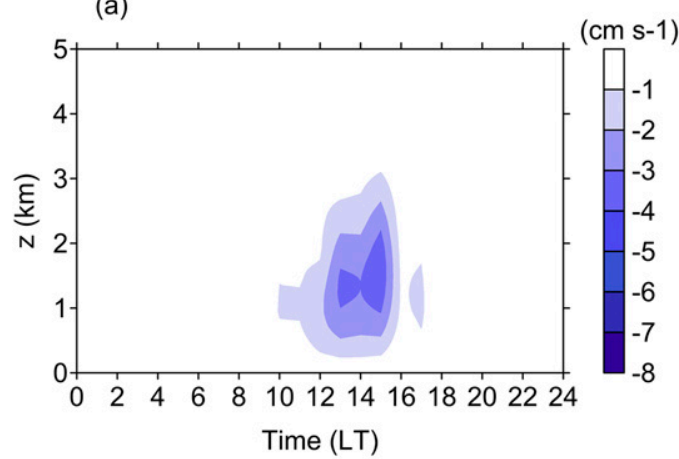

(c)

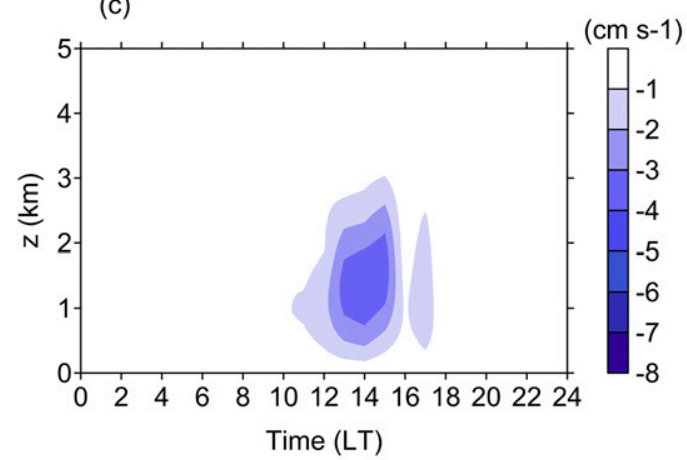

(e)

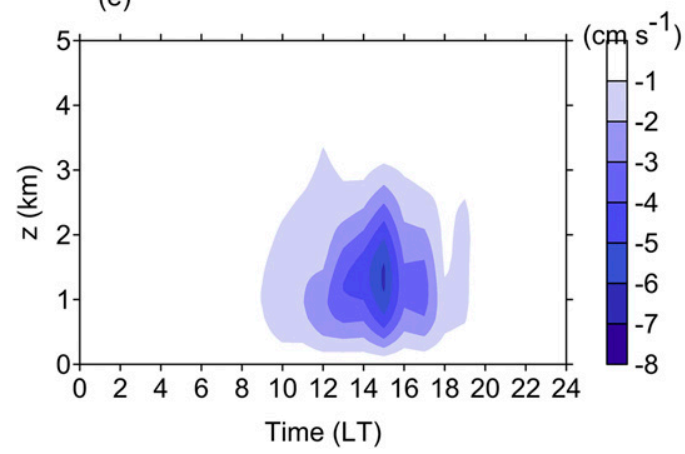

(b)

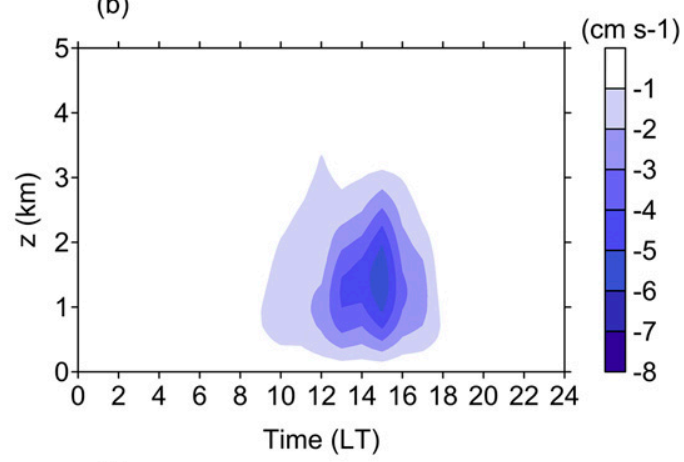

(d)

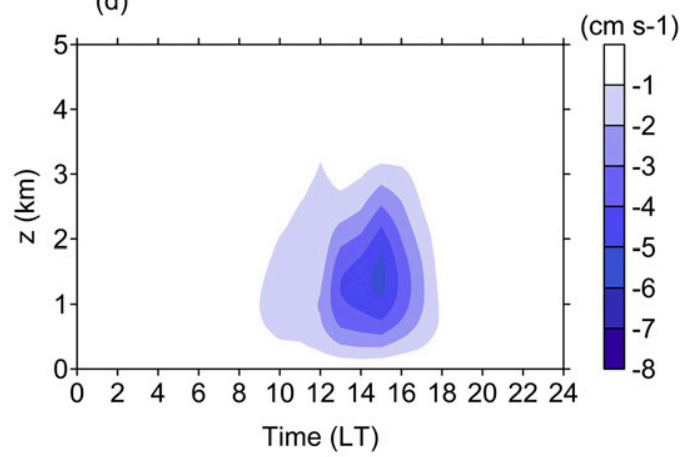

(f)

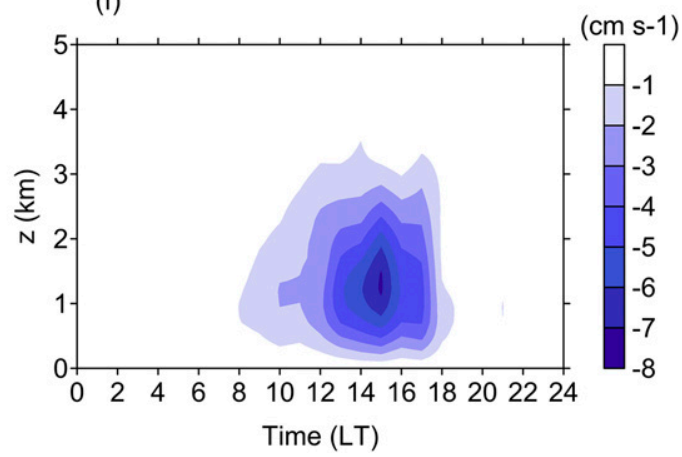

FIG. 17. As in Fig. 13, but for vertical velocity.

Multiyear/decade simulations are needed to understand the potential impact of cool roofs and green roofs on precipitation.

\section{Summary and conclusions}

This paper uses a regional climate model (WRF-NoahSLUCM) to investigate the effectiveness of different mitigation strategies (cool roofs and green roofs) in a very hot summer in the Yangtze River delta, China. This study also tries to determine the impact of urban heat island mitigation on the regional climate. Unlike previous studies that only focused on heat wave episodes that were several days long, this paper focused on a hot summer, when a heat wave of one and a half months occurred.
With the physically based single-layer urban canopy model, the WRF Model represented the summer climate conditions well. The modifications to the roof surface changed the urban surface radiation balance and then modified the local surface energy budget. By reducing the surface sensible heat flux, both cool roofs and green roofs led to lower surface skin temperatures and near-surface air temperatures. Increasing the roof albedo to 0.5 caused a similar effectiveness as covering $25 \%$ of urban roofs with vegetation, and increasing the roof albedo to 0.7 caused a similar near-surface air temperature decrease as would $50 \%$ green roof coverage. By increasing the surface latent heat flux via more evapotranspiration, green roofs led to higher nearsurface specific humidity. The near-surface relative 
(a)

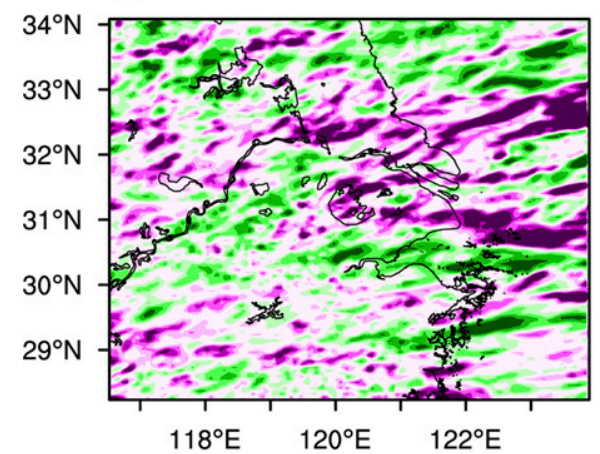

(c)

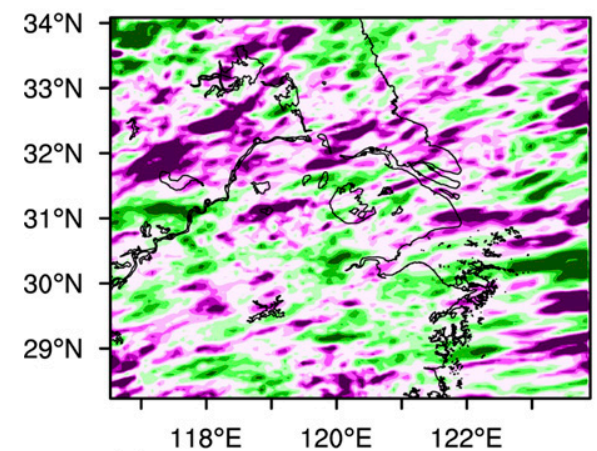

(e)

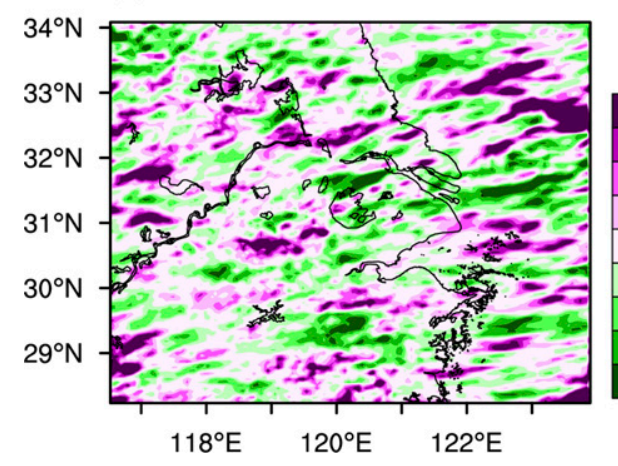

(b)
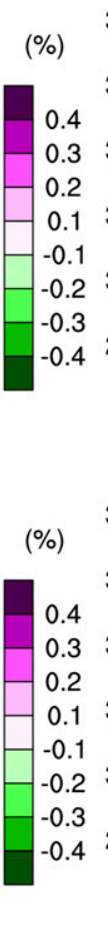

(\%)

(d)

(f)
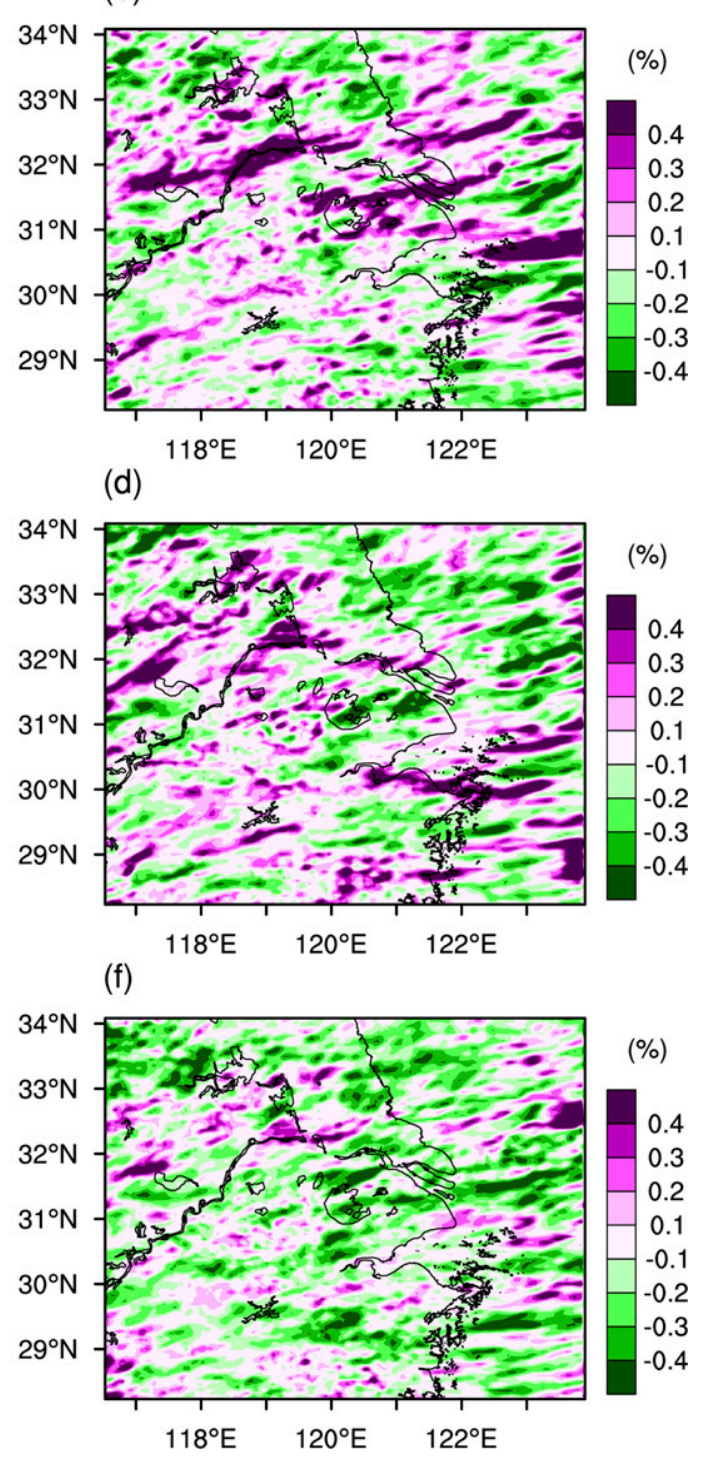

FIG. 18. As in Fig. 7, but for the change ratio of season (JJA) total precipitation.

humidity increased in both cool roof and green roof experiments because of the combination of the impacts of increases in specific humidity and decreases in air temperature.

The regional impacts of cool roofs and green roofs were evaluated using the regional effect index. The regional effect could be found in both near-surface air temperatures and surface specific/relative humidity when the roofs were covered with high albedo materials or the green roofs reached a higher fraction (greater than $50 \%$ ). The changes in the vertical profiles of temperature cause a more stable atmospheric boundary layer over urban areas. This resulted in the decrease in the planetary boundary layer height; the seasonally averaged decrease of the model-diagnosed PBLH could reach more than $150 \mathrm{~m}$ over the urban area. The impacts on the PBLH also had a regional effect and caused a decrease in the PBLH in the areas surrounding cities. The decrease in air temperature and increase in specific/ relative humidity due to the urban heat island mitigations extended from the urban surface to the top of the boundary layer; at the same time, the crossover phenomena occurred above the boundary layer due to decreases in the vertical wind speed.

The numerical simulations showed that both cool roofs and green roofs are effective methods to modify the urban climate, and even the surrounding rural area may benefit from the mitigation of the urban heat island. 
However, several important points still need to be investigated in the next stage. Both cool roofs and green roofs reduce the vertical mixing over urban areas; this may increase the cleaning time of air pollutants in cities. Previous studies also documented that urbanization impacted precipitation on a regional scale (Trusilova et al. 2008; Zhang et al. 2010); the modification in the urban boundary layer in different mitigation strategies also impacts the temperature and moisture profiles over urban areas and has potential impacts on cloud and precipitation processes. Most current studies have focused only on heat wave episodes or the summer season, while the potential long-term (year or decade scale) impacts of different mitigation strategies also need to be investigated in future work, especially for the understanding of impacts on precipitation processes, even though only negligible influence was observed in our simulations.

Acknowledgments. This paper is supported by the Chinese National Key Research and Development Program (Grants 2016YFA0600303 and 2016YFC0200501) and the National Natural Science Foundation of China (Grants 41375014 and 41675016). We acknowledge the Land Processes Distributed Active Archive Center (LP DAAC, https://lpdaac.usgs.gov/) for the MODIS data used in this paper. The MODIS MCD12Q1 data product was retrieved from the online data pool, courtesy of the NASA Land Processes Distributed Active Archive Center (LP DAAC), USGS/Earth Resources Observation and Science (EROS) Center, Sioux Falls, South Dakota, https://lpdaac.usgs.gov/data_access/data_pool.

\section{REFERENCES}

Aflaki, A., M. Mirnezhad, A. Ghaffarianhoseini, A. Ghaffarianhoseini, H. Omrany, Z.-H. Wang, and H. Akbari, 2016: Urban heat island mitigation strategies: A state-of-the-art review on Kuala Lumpur, Singapore and Hong Kong. Cities, 62, 131-145, doi:10.1016/j.cities.2016.09.003.

Barlage, M., S. Miao, and F. Chen, 2016: Impact of physics parameterizations on high-resolution weather prediction over two Chinese megacities. J. Geophys. Res. Atmos., 121, 4487-4498, doi:10.1002/2015JD024450.

Basara, J. B., H. G. Basara, B. G. Illston, and K. C. Crawford, 2010: The impact of the urban heat island during an intense heat wave in Oklahoma City. Adv. Meteor., 2010, 230365, doi:10.1155/2010/230365.

Bornstein, R. D., 1968: Observations of the urban heat island effect in New York City. J. Appl. Meteor., 7, 575-582, doi:10.1175/ 1520-0450(1968)007<0575:OOTUHI >2.0.CO;2.

Bougeault, P., and P. Lacarrere, 1989: Parameterization of orographyinduced turbulence in a mesobeta-scale model. Mon. Wea. Rev., 117, 1872-1890, doi:10.1175/1520-0493(1989)117<1872: POOITI $>2.0 . \mathrm{CO} ; 2$.

Chen, F., and J. Dudhia, 2001: Coupling an advanced land surfacehydrology model with the Penn State-NCAR MM5 modeling system. Part I: Model implementation and sensitivity. Mon.
Wea. Rev., 129, 569-585, doi:10.1175/1520-0493(2001)129<0569: CAALSH $>2.0 . \mathrm{CO} ; 2$.

—, S. Miao, M. Tewari, J.-W. Bao, and H. Kusaka, 2011a: A numerical study of interactions between surface forcing and sea breeze circulations and their effects on stagnation in the greater Houston area. J. Geophys. Res., 116, D12105, doi:10.1029/2010JD015533.

— and Coauthors, 2011b: The integrated WRF/urban modelling system: Development, evaluation, and applications to urban environmental problems. Int. J. Climatol., 31, 273-288, doi:10.1002/joc. 2158.

Coumou, D., and S. Rahmstorf, 2012: A decade of weather extremes. Nat. Climate Change, 2, 491-491, doi:10.1038/ nclimate1452.

Ek, M. B., K. E. Mitchell, Y. Lin, E. Rogers, P. Grunmann, V. Koren, G. Gayno, and J. D. Tarpley, 2003: Implementation of Noah land surface model advances in the National Centers for Environmental Prediction operational mesoscale Eta model. J. Geophys. Res., 108, 8851, doi:10.1029/2002JD003296.

Gershunov, A., D. R. Cayan, and S. F. Iacobellis, 2009: The great 2006 heat wave over California and Nevada: Signal of an increasing trend. J. Climate, 22, 6181-6203, doi:10.1175/ 2009JCLI2465.1.

Gosling, S. N., G. R. McGregor, and A. Páldy, 2007: Climate change and heat-related mortality in six cities. Part 1: Model construction and validation. Int. J. Biometeorol., 51, 525-540, doi:10.1007/s00484-007-0092-9.

,$- \ldots$, and J. A. Lowe, 2009: Climate change and heat-related mortality in six cities. Part 2: Climate model evaluation and projected impacts from changes in the mean and variability of temperature with climate change. Int. J. Biometeorol., 53, 31-51, doi:10.1007/s00484-008-0189-9.

Grawe, D., H. L. Thompson, J. A. Salmond, X.-M. Cai, and K. H. Schlünzen, 2013: Modelling the impact of urbanisation on regional climate in the Greater London area. Int. J. Climatol., 33, 2388-2401, doi:10.1002/joc.3589.

Grimmond, S., 2007: Urbanization and global environmental change: Local effects of urban warming. Geogr. J., 173, 83-88, doi:10.1111/j.1475-4959.2007.232_3.x.

Guirguis, K., A. Gershunov, A. Tardy, and R. Basu, 2014: The impact of recent heat waves on human health in California. J. Appl. Meteor. Climatol., 53, 3-19, doi:10.1175/ JAMC-D-13-0130.1.

Gutiérrez, E., J. E. González, A. Martilli, R. Bornstein, and M. Arend, 2015: Simulations of a heat-wave event in New York City using a multilayer urban parameterization. J. Appl. Meteor. Climatol., 54, 283-301, doi:10.1175/ JAMC-D-14-0028.1.

Hansen, J. E., R. Ruedy, M. Sato, and K. K. Lo, 2010: Global surface temperature change. Rev. Geophys., 48, RG4004, doi:10.1029/2010RG000345.

Harlan, S. L., A. J. Brazel, L. Prashad, W. L. Stefanov, and L. Larsen, 2006: Neighborhood microclimates and vulnerability to heat stress. Soc. Sci. Med., 63, 2847-2863, doi:10.1016/ j.socscimed.2006.07.030.

Huang, Q., and Y. Lu, 2015: The effect of urban heat island on climate warming in the Yangtze River delta urban agglomeration in China. Int. J. Environ. Res. Public Health, 12, 8773-8789, doi:10.3390/ijerph120808773.

Kang, H.-Q., B. Zhu, T. Zhu, J.-L. Sun, and J.-J. Ou, 2014: Impact of megacity Shanghai on the urban heat-island effects over the downstream city Kunshan. Bound.-Layer Meteor., 152, 411-426, doi:10.1007/s10546-014-9927-1. 
Kong, F., W. Yan, G. Zheng, H. Yin, G. Cavan, W. Zhan, N. Zhang, and L. Cheng, 2016: Retrieval of three-dimensional tree canopy and shade using terrestrial laser scanning (TLS) data to analyze the cooling effect of vegetation. Agric. For. Meteor., 217, 22-34, doi:10.1016/j.agrformet.2015.11.005.

Kovats, R. S., and S. Hajat, 2008: Heat stress and public health: A critical review. Annu. Rev. Public Health, 29, 41-55, doi:10.1146/annurev.publhealth.29.020907.090843.

Kusaka, H., and F. Kimura, 2004: Coupling a single-layer urban canopy model with a simple atmospheric model: Impact on urban heat island simulation for an idealized case. J. Meteor. Soc. Japan, 82, 67-80, doi:10.2151/jmsj.82.67.

—, H. Kondo, Y. Kikegawa, and F. Kimura, 2001: A simple single-layer urban canopy model for atmospheric models: Comparison with multi-layer and slab models. Bound.-Layer Meteor., 101, 329-358, doi:10.1023/A:1019207923078.

_ M. Mara, and Y. Takane, 2012a: Urban climate projection by the WRF model at 3-km horizontal grid increment: Dynamical downscaling and predicting heat stress in the 2070's August for Tokyo, Osaka, and Nagoya metropolises. J. Meteor. Soc. Japan, 90B, 47-63, doi:10.2151/jmsj.2012-B04.

_, F. Chen, M. Tewari, J. Dudhia, D. O. Gill, M. G. Duda, W. Wang, and Y. Miya, 2012b: Numerical simulation of urban heat island effect by the WRF model with $4-\mathrm{km}$ grid increment: An inter-comparison study between the urban canopy model and slab model. J. Meteor. Soc. Japan, 90B, 33-45, doi:10.2151/jmsj.2012-B03.

Lelieveld, J., Y. Proestos, P. Hadjinicolaou, M. Tanarhte, E. Tyrlis, and G. Zittis, 2016: Strongly increasing heat extremes in the Middle East and North Africa (MENA) in the 21st century. Climatic Change, 137, 245-260, doi:10.1007/s10584-016-1665-6.

Li, D., and E. Bou-Zeid, 2013: Synergistic interactions between urban heat islands and heat waves: The impact in cities is larger than the sum of its parts. J. Appl. Meteor. Climatol., 52, 2051-2064, doi:10.1175/JAMC-D-13-02.1.

—, and _ 2014: Quality and sensitivity of high-resolution numerical simulation of urban heat islands. Environ. Res. Lett., 9, 055001, doi:10.1088/1748-9326/9/5/055001.

,-- , and M. Oppenheimer, 2014: The effectiveness of cool and green roofs as urban heat island mitigation strategies. Environ. Res. Lett., 9, 055002, doi:10.1088/1748-9326/9/5/055002.

Loikith, P. C., and A. J. Broccoli, 2012: Characteristics of observed atmospheric circulation patterns associated with temperature extremes over North America. J. Climate, 25, 7266-7281, doi:10.1175/JCLI-D-11-00709.1.

Martilli, A., A. Clappier, and M. W. Rotach, 2002: An urban surface exchange parameterisation for mesoscale models. Bound. Layer Meteor., 104, 261-304, doi:10.1023/A:1016099921195.

Meehl, G. A., and C. Tebaldi, 2004: More intense, more frequent, and longer lasting heat waves in the 21 st century. Science, $\mathbf{3 0 5}$, 994-997, doi:10.1126/science.1098704.

Miao, S., and F. Chen, 2008: Formation of horizontal convective rolls in urban areas. Atmos. Res., 89, 298-304, doi:10.1016/ j.atmosres.2008.02.013.

— , P. Li, and X. Wang, 2009: Building morphological characteristics and their effect on the wind in Beijing. Adv. Atmos. Sci., 26, 1115-1124, doi:10.1007/s00376-009-7223-7.

Perkins, S. E., and L. V. Alexander, 2013: On the measurement of heat waves. J. Climate, 26, 4500-4517, doi:10.1175/JCLI-D-12-00383.1.

, - - and J. R. Nairn, 2012: Increasing frequency, intensity and duration of observed global heat waves and warm spells. Geophys. Res. Lett., 39, L20714, doi:10.1029/2012GL053361.
Roldan, E., M. Gomez, M. R. Pino, J. Pórtoles, C. Linares, and J. Díaz, 2016: The effect of climate-change-related heat waves on mortality in Spain: Uncertainties in health on a local scale. Stochastic Environ. Res. Risk Assess., 30, 831-839, doi:10.1007/ s00477-015-1068-7.

Rosenfeld, A. H., H. Akbari, S. Bretz, B. L. Fishman, D. M. Kurn, D. Sailor, and H. Taha, 1995: Mitigation of urban heat islands: Materials, utility programs, updates. Energy Build., 22, 255-265, doi:10.1016/0378-7788(95)00927-P.

Salamanca, F., A. Krpo, A. Martilli, and A. Clappier, 2010: A new building energy model coupled with an urban canopy parameterization for urban climate simulations-Part I: Formulation, verification, and sensitivity analysis of the model. Theor. Appl. Climatol., 99, 331-344, doi:10.1007/ s00704-009-0142-9.

— , A. Martilli, M. Tewari, and F. Chen, 2011: A study of the urban boundary layer using different urban parameterizations and highresolution urban canopy parameters with WRF. J. Appl. Meteor. Climatol., 50, 1107-1128, doi:10.1175/2010JAMC2538.1.

Schneider, A., and C. M. Mertes, 2014: Expansion and growth in Chinese cities, 1978-2010. Environ. Res. Lett., 9, 024008, doi:10.1088/1748-9326/9/2/024008.

_- M. A. Friedl, and D. Potere, 2009: A new map of global urban extent from MODIS satellite data. Environ. Res. Lett., 4, 044003, doi:10.1088/1748-9326/4/4/044003.

Sharma, A., P. Conry, H. J. S. Fernando, A. F. Hamlet, J. J. Hellmann, and F. Chen, 2016: Green and cool roofs to mitigate urban heat island effects in the Chicago metropolitan area: Evaluation with a regional climate model. Environ. Res. Lett., 11, 064004, doi:10.1088/1748-9326/11/6/064004.

Shepherd, J. M., 2005: A review of current investigations of urbaninduced rainfall and recommendations for the future. Earth Interact., 9, 1-27, doi:10.1175/EI156.1.

Silva, H., P. E. Phelan, and J. S. Golden, 2010: Modeling effects of urban heat island mitigation strategies on heat-related morbidity: A case study for Phoenix, Arizona, USA. Int. J. Biometeorol., 54, 13-22, doi:10.1007/s00484-009-0247-y.

Smith, T. T., B. F. Zaitchik, and J. M. Gohlke, 2013: Heat waves in the United States: Definitions, patterns and trends. Climatic Change, 118, 811-825, doi:10.1007/s10584-012-0659-2.

Sparks, N., and R. Toumi, 2015: Numerical simulations of daytime temperature and humidity crossover effects in London. Bound.-Layer Meteor., 154, 101-117, doi:10.1007/ s10546-014-9964-9.

Sugawara, H., H. Tanaka, K. Narita, T. Nakano, and T. Mikami, 2008: How much cool air does an urban green park produce? Geogr. Rep. Tokyo Metropolitan Univ., 43, 83-89.

Sun, T., E. Bou-Zeid, Z.-H. Wang, E. Zerba, and G.-H. Ni, 2013: Hydrometeorological determinants of green roof performance via a vertically-resolved model for heat and water transport. Build. Environ., 60, 211-224, doi:10.1016/ j.buildenv.2012.10.018.

, — , and G.-H. Ni, 2014: To irrigate or not to irrigate: Analysis of green roof performance via a vertically-resolved hygrothermal model. Build. Environ., 73, 127-137, doi:10.1016/j.buildenv.2013.12.004.

Sun, Y., X. Zhang, F. W. Zwiers, L. Song, H. Wan, T. Hu, H. Yin, and G. Ren, 2014: Rapid increase in the risk of extreme summer heat in Eastern China. Nat. Climate Change, 4, 10821085, doi:10.1038/nclimate2410.

,,-- G. Ren, F. W. Zwiers, and T. Hu, 2016: Contribution of urbanization to warming in China. Nat. Climate Change, 6 , 706-709, doi:10.1038/nclimate2956. 
Susca, T., S. R. Gaffin, and G. R. Dell'Osso, 2011: Positive effects of vegetation: Urban heat island and green roofs. Environ. Pollut., 159, 2119-2126, doi:10.1016/j.envpol.2011.03.007.

Tan, J., and Coauthors, 2010: The urban heat island and its impact on heat waves and human health in Shanghai. Int. J. Biometeor., 54, 75-84, doi:10.1007/s00484-009-0256-x.

Tanarhte, M., P. Hadjinicolaou, and J. Lelieveld, 2015: Heat wave characteristics in the eastern Mediterranean and Middle East using extreme value theory. Climate Res., 63, 99-113, doi:10.3354/cr01285.

Trusilova, K., M. Jung, G. Churkina, U. Karstens, M. Heimann, and M. Claussen, 2008: Urbanization impacts on the climate in Europe: Numerical experiments by the PSU-NCAR Mesoscale Model (MM5). J. Appl. Meteor. Climatol., 47, 1442-1455, doi:10.1175/2007JAMC1624.1.

Wang, J., Z. Yan, X.-W. Quan, and J. Feng, 2016: Urban warming in the 2013 summer heat wave in eastern China. Climate Dyn., 48, 3015-3033, doi:10.1007/s00382-016-3248-7.

Wang, W., W. Zhou, and D. Chen, 2014: Summer high temperature extremes in southeast China: Bonding with the El NiñoSouthern Oscillation and East Asian summer monsoon coupled system. J. Climate, 27, 4122-4138, doi:10.1175/ JCLI-D-13-00545.1.

Wang, X., and Y. Gong, 2010: The impact of an urban dry island on the summer heat wave and sultry weather in Beijing City. Chin. Sci. Bull., 55, 1657-1661, doi:10.1007/ s11434-010-3088-5.

Wang, Y., U. Berardi, and H. Akbari, 2016: Comparing the effects of urban heat island mitigation strategies for Toronto, Canada. Energy Build., 114, 2-19, doi:10.1016/j.enbuild.2015.06.046.
Wang, Z. H., E. Bou-Zeid, and J. A. Smith, 2013: A coupled energy transport and hydrological model for urban canopies evaluated using a wireless sensor network. Quart. J. Roy. Meteor. Soc., 139, 1643-1657, doi:10.1002/qj.2032.

Wu, J., Y. Zhou, Y. Gao, J. S. Fu, B. A. Johnson, C. Huang, Y.-M. Kim, and Y. Liu, 2014: Estimation and uncertainty analysis of impacts of future heat waves on mortality in the eastern United States. Environ. Health Perspect., 122, 10-16, doi:10.1289/ehp.1306670.

Yang, J., Z.-H. Wang, F. Chen, S. Miao, M. Tewari, J. A. Voogt, and S. Myint, 2015: Enhancing hydrologic modelling in the coupled Weather Research and Forecasting-urban modelling system. Bound.-Layer Meteor., 155, 87-109, doi:10.1007/ s10546-014-9991-6.

Zhang, N., Z. Q. Gao, X. M. Wang, and Y. Chen, 2010: Modeling the impact of urbanization on the local and regional climate in Yangtze River delta, China. Theor. Appl. Climatol., 102, 331-342, doi:10.1007/s00704-010-0263-1.

— L. F. Zhu, and Y. Zhu, 2011: Urban heat island and boundary layer structures under hot weather synoptic conditions: A case study of Suzhou City, China. Adv. Atmos. Sci., 28, 855-865, doi:10.1007/s00376-010-0040-1.

_, X. Wang, Y. Chen, W. Dai, and X. Wang, 2016: Numerical simulations on influence of urban land cover expansion and anthropogenic heat release on urban meteorological environment in Pearl River delta. Theor. Appl. Climatol., 126, 469-479, doi:10.1007/s00704-015-1601-0.

Zhou, Y., and J. M. Shepherd, 2010: Atlanta's urban heat island under extreme heat conditions and potential mitigation strategies. Nat. Hazards, 52, 639-668, doi:10.1007/ s11069-009-9406-z. 